\title{
Optimization of the Novel Bisulfite Steeping Method by Response Surface Methodology for Natural Starch Synthesis From Oil Palm Trunk Biomass
}

\section{Zaber Ahmed}

School of Civil Engineering, University Sains Malaysia

Mohd Suffian Yusoff ( $\nabla$ suffian@usm.my)

School of Civil Engineering, Engineering Campus, Universiti Sains Malaysia, 14300 Nibong Tebal,

Penang, Malaysia

\section{Nurul Hana Mokhtar Kamal}

School of Civil Engineering, University Sains Malaysia

\section{Hamidi Abdul Aziz}

Professor, School o Civil Engineering, University Sains Malaysia

\section{Research}

Keywords: oil palm trunk biomass, response surface methodology, Central composite design, bisulfite steeping, Scanning electron microscopy, X-ray diffraction

Posted Date: September 4th, 2020

DOl: https://doi.org/10.21203/rs.3.rs-61539/v1

License: (c) (1) This work is licensed under a Creative Commons Attribution 4.0 International License. Read Full License 


\title{
Optimization of the Novel Bisulfite Steeping Method by Response Surface Methodology for Natural Starch Synthesis from Oil Palm Trunk Biomass
}

\author{
Zaber Ahmed ${ }^{1}$, Mohd Suffian Yusoff $^{1}$, Mokhtar Kamal N.H ${ }^{\mathbf{1}}$, Hamidi Abdul Aziz ${ }^{1}$ \\ ${ }^{1}$ School of Civil Engineering, Engineering Campus, Universiti Sains \\ Malaysia, 14300 Nibong Tebal, Penang, Malaysia \\ E-mail: suffian@usm.my
}

\begin{abstract}
Malaysia is the 2nd largest in palm oil export, and after overcoming economic age (average 25 years), the palm oil trees entail to replace usually. Therefore, a massive quantity of palm oil trunk biomass, containing a significant amount of starch, is available as bio-waste annually. The efficient extraction of this starch (carbohydrate polymer) would be worthwhile concerning the environment, economy, conversion of biowaste to bioresources, and waste dumping challenges. Central composite design executed an experimental model design, evaluated the impacts of process variables and their interaction through response surface methodology to optimize the novel bisulfite steeping method for starch synthesis. Design-Expert software performed the data analysis. The developed quadratic models for four factors (Strength of Sodium bisulfite solution, steeping hour, mixing ratio with the bisulfite solution and ultra-pure water) and one response (\% Yield), demonstrated that a significant starch yield (13.54\%) is achievable utilizing $0.74 \%$ bisulfite solution, 5.6 steeping hours, for 1.6 and 0.6 mixing ratio with the bisulfite solution and ultra-pure water respectively. Experimental outcomes were quite consistent with the predicted model, which eventually sustains the significance of this method. Malvern Zetasizer test revealed a bimodal granular distribution for starch, with $7.15 \mu \mathrm{m}$ of hydrodynamic size. Starch morphology was determined by scanning electron microscopy. X-ray diffraction investigation exhibits an A-type model, specifying persistent characteristics of extracted starch.
\end{abstract}

Keywords: oil palm trunk biomass, response surface methodology, Central composite design, bisulfite steeping, Scanning electron microscopy, X-ray diffraction

\section{Introduction}

Oil palm (Elaeis guineensis Jacq.), a well-known monocotyledon perennial oilseed crop that is native to Guinea Coast of West Africa and widely planted across 42 equatorial countries especially Malaysia 
and Indonesia (Murai and Kondo, 2010). In 2019, Malaysia was the second among the global major palm oil producer countries, produced 20.5 million metric tons of crude oil (Kushairi et al., 2019) with 2.13 metric tons of palm kernel oil while the ultimate plantation area of the palm oil trees was around 6.6 million hectares (Tan and Ho, 2019). Malaysia is continuing to hold its position in the world for palm oil production as well as export, currently attributing to about $11 \%$ oil production and $27 \%$ of export trade of the world. Besides this, the oil palm industry offers employment and livelihoods to a massive number of people, which is around one million. In tandem with increasing palm oil production because of its unique application as well as incredible requirement, the corresponding increase of generated residues also inevitably happening, which will reach up to 110 million tons by 2020 , almost $86 \%$ out of the total national annual biomass production (Dalton, Mohamed and Chikere, 2017). If not been converted to bioresource, these huge bio-wastes will be a severe environmental burden and barrier to achieving the sustainable development goal (SDG). Meanwhile, UN already linked directly almost 12 (twelve) goals to solid waste management globally, among the 17 (seventeen) Sustainable Development Goals (SDGs) (Rodić and Wilson, 2017).

After an average of 25 years of economic life span, oil palm trees require replacement essentially with higher-yielding young palms. Although agro-wastes are commonly used for animal feed (Kumar et al., 2017) but open burning of oil palm trunks is a common phenomenon for rapid discarding at replantation time. Formation of heavy haze, is a well-known impact of open burning ultimately, which is responsible for significant impact on atmospheric chemistry, global warming through increasing carbon emission (Wei et al., 2019) and human health (Ahmed, Guo and Zhao, 2016) while remaining oil palm bio-wastes are discarded to mulch, and replenish the land without any further usage (Yanita and Qoirina, 2019). Decently about only 22\% of palm oil trunk biomass is used in veneer manufacturing for plywood, medium-density fibreboards (MDF), and low-quality kiln-dried lumber (Abdullah et al., 2012) and shockingly the rest volume of biomass is causing the severe environmental declination (Hamzah, Tokimatsu and Yoshikawa, 2019).

Numerous studies affirmed the existence of a significant quantity of starch in palm oil trunk (OPT) biomass, which is a carbohydrate polymer of general formula $\left(\mathrm{C}_{6} \mathrm{H}_{10} \mathrm{O}_{5}\right)_{\mathrm{n}}$, stored inside the highly lignified parenchymatic cells (Murai and Kondo, 2010). Amylose (AM), amylopectin (AP) are the two 
major elements of starch, while stipulates the basic nutrition for humans as well as animals. Efficient extraction of natural starch from oil palm biomass will ensure the reduction of huge post-harvest processing cost (approximately RM 560 per dry tonne) (Syamsul Bahri, 2016) and further reuse in any other purpose, i.e. as food, as a natural coagulant for leachate and wastewater treatment (Yusoff et al., 2019), to prepare particle boards, etc. Even it is also possible to apply broadly in chemical, pharmaceuticals or cosmetics sector, paper and corrugation industries (Wu et al., 2020) because of its extra ordinary composition eventually, which will convert this waste to beneficial bioresources. Extracted starch typically consists of 20-367\% linear and slightly branched AM with $0.41 \%-0.9 \%$ protein (H'ng et al., 2011). Figure 1 displays the typical bonding arrangement of OPT.

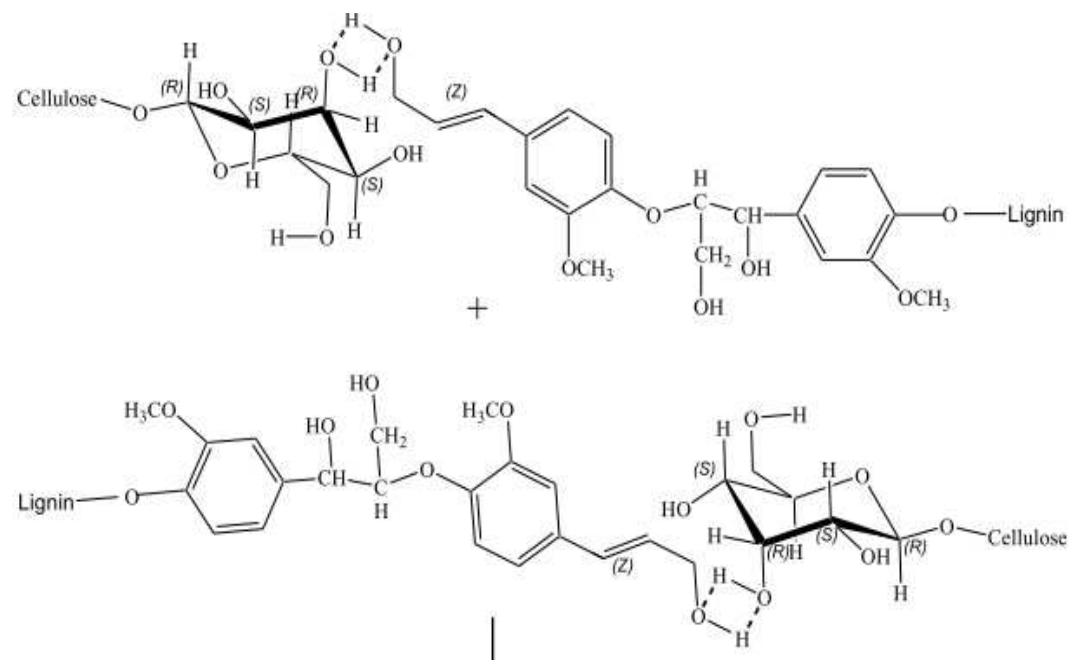

Fig. 1. Bonding arrangement of oil palm trunk (Nadhari et al., 2013)

The highest reported OPTS yield was $7.15 \%$ of OPT dry weight by using Modified Dos Method (Noor et al., 1999), beating C5/C6 sugars steeping method with lactic acid (1.7\% yield) and conventional C5/C6 sugars steeping method (H'ng et al., 2011) although OPT contains 16-17\% of extractable starch (Nadhari et al., 2013). To date, there is no comprehensive explanation is available on implementing the bisulfite steeping method for the extraction of starch from oil palm biomass. Thus, about 1 million ton of OPTS could be harvested annually from the OPT waste by using current technology, while OPTS yield could be increased above 6-7 tonnes per hectare through optimization of the synthesis process, which is quite higher than starch production from sago (4-5 tonnes) (Zhu, 2019), cassava (2 tonnes) and corn (1 tonne). 
So, the current research emphasized to investigate the convenience of the novel bisulfite steeping method focusing the key experimental factors for optimising the synthesis of natural starch from the discarded oil palm trunk biomass. The enhancement as well as the optimization of the extraction method to maximize the starch synthesis, were performed applying a contemporary approach of mathematical analysis i.e. response surface methodology (RSM). Central composite design (CCD) of Design-Expert software (version 7.0) performed the experimental design and generated the mathematical models for determining the optimum conditions. Analysis of variance (ANOVA) from response surface methodology (RSM) offers the statistical outcomes with diagnostic checking, which makes it possible for the researchers to justify the capability of the models. Therefore, the starch yield was evaluated through this study as a sole response in terms of four experimental parameters, i.e. the strength of bisulfite solution, steeping duration, mixing ratio with bisulfite solution as well as ultra-pure water (UPW).

\section{Experimental Methodology}

\subsection{Collection of Oil Palm Trunk (OPT)}

During the replantation period, discarded oil palm trunks (OPT) over 25 years old were obtained between September 2019 and February 2020 for starch extraction through slicing, shredding as well as debarking. Engineering Campus of University Sains Malaysia (USM), situated at Nibong Tebal, Pulau Pinang State, Malaysia, was the collection spot of OPT (Fig.2), which was transported immediately to the environmental engineering laboratory, School of Civil Engineering to preserve the samples initially at room temperature. After debarking, the freshly chopped trunks were sliced again into stiff blocks of around $8 \mathrm{~cm}$ to $12 \mathrm{~cm}$ size.

\subsection{Reagents and Chemicals}

Analytical grade chemicals and reagents, obtained based on the Standard Method in order to Analysis of Water and Wastewater (APHA, 2012). This study applied collected reagents and chemicals throughout the experimental phase of extracting the natural starch from palm oil trunk. AR Bendosen, PA, HmbG, and Rashaki Venture Sdn Bhd served Sodium Bisulfite $\left(\mathrm{NaHSO}_{3}\right)$ of 99.8\% purity, Acetone, and $16 \mathrm{~mm}$ Polypropylene Tubes, respectively as per experimental requirement. Veolia Water Solutions \& Technologies Ltd, UK produced distilled water (DW) while PURELAB Option-Q provided Ultra-pure water (UPW) for this study. Phong Heng is the provider of the Filtration apparatus, 1000ml. (with flask, 
funnel, filter holder, clamp), whereas Bio flow company supplied Glass fiber Filter paper (GF/A) 1.6 $\mu$, $47 \mathrm{~mm}$.

\subsection{Extraction of Natural Starch from Palm Oil Trunk (OPT)}

The current experimental study investigated the optimization of the bisulfite steeping method for starch yield from palm oil trunk biomass as a natural polymer.

After washing throughout, $500 \mathrm{gm}$ of freshly shredded and uniformly chipped (2-3 cm blocks) OPT meal were steeped under Sodium bisulfite (BS) solution. The strength of BS solution varied from $0.2 \%$ to 1\% (Madruga et al., 2014) while the variable steeping duration was 2 hrs to $10 \mathrm{hrs}$ (Maniglia and TapiaBlácido, 2016) at a different mixing ratio of 1:1, 1:1.5 and 1:2 (with the initial weight of OPT). The whole study followed the room temperature at original $\mathrm{pH}$. The accumulation of sodium bisulfite solution crumbles the protein/starch matrices and restrains the growth of microorganisms (Sulaiman et al., 2013). While the steeping duration was over, the OPT meals were macerated homogenously dividing into several batches (up to 5 mins each batch) using an industrial grinder, and the slurry was placed into a nylon screen. After squeezing the slurry fairly, the filtrates were placed in a plastic dish. For extracting the residual starch, the OPT remainders passed through a similar procedure. The ultimate filtrates were screened through $212 \mu \mathrm{m}$ sieve and allowed for $2 \mathrm{hrs}$ settlement. After $2 \mathrm{hrs}$ settlement, the supernatant was removed by leaning the dish, and 2 liters of aquatic sodium bisulfite solution was blended completely with the precipitate while allowed to settle again for $2 \mathrm{hrs}$. Discarding the floated like earlier, the residue was mixed with ultra-pure water at a variable mixing ratio (from 1:0.3 to 1:0.7 based on the initial weight of OPT) for washing. Later, this mixture was centrifuged at 3,500 rpm up to 10 mins (Yusoff et al., 2019). The remaining starch precipitates were filtered after centrifugation through vacuum filtration attired with a $1.6 \mu \mathrm{m}$ opening size fiberglass filter for rinsing and refining the yielded starch. $100 \mathrm{~mL}$ of acetone was applied for further washing and removing water from the refined starch sediment. Finally, the washed starch was sun-dried for $24 \mathrm{hrs}$ and crushed lightly to get fine powder-like starch (Fig. 2). After passing through a 70-mesh sieve the weight of ground starch was measured to calculate the ultimate yield $(\%)$ with respect to the initial weight of trunk biomass and stored in air-tight containers until use. 

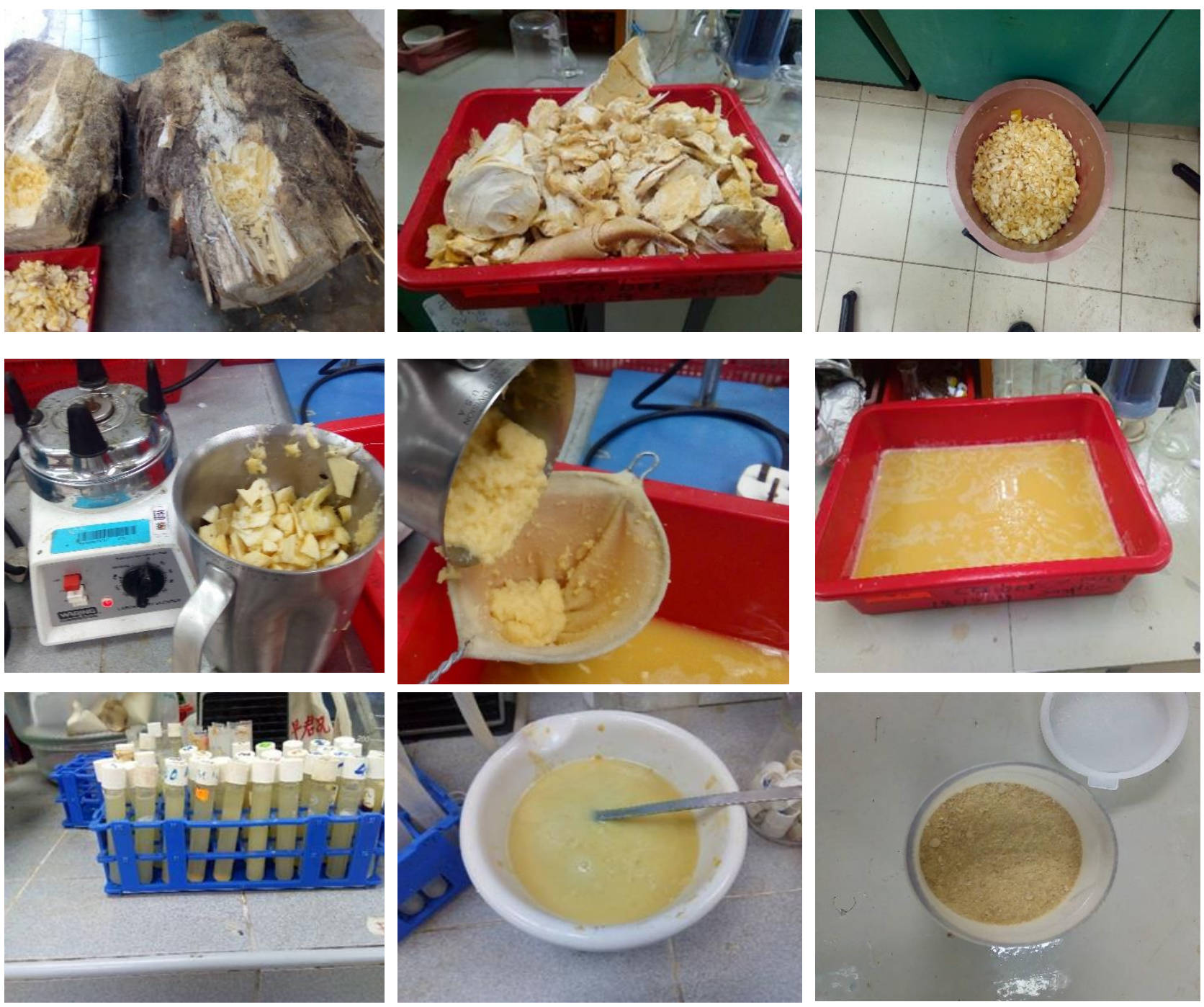

Figure 2 Extraction of starch from oil palm trunk

\subsection{Design of Experiment, Modeling and Data Analysis}

Analytical Software Design-Expert (version 7.0) performed the experimental design, mathematical modelling, as well as the data analysis in the current study. Central composite design (CCD) from the Response Surface Methodology (RSM) carried out the optimization of the 4 (four) major experimental factors, i.e. the strength of bisulfite (BS) solution, steeping duration, mixing ratio of OPT with BS solution, and mixing ratio with ultra-pure water (UPW) coded as A, B, C, D, and one response, i.e. starch yield (\% initial weight of OPT). Preliminary batch studies were performed continuously until the process response (starch yield) had a satisfactory outcome, to achieve a leaner range of operating parameters in advance of applying central composite design for the experimental runs. Following the batch studies, the preferred ranges of experimental parameters were; strength of BS solution $0.2 \%$ to $1 \%$, steeping duration 4hrs to $8 \mathrm{hrs}$, mixing ratio with BS solution 1:1 to1:2 and mixing ratio with UPW 1:0.4 to 1:0.6 
accordingly for optimising the starch yield. Table 2 displays the central composite design (CCD) for the operating parameters in terms of their primary unit and terms of $2 \mathrm{k}$ factorial design considering $\mathrm{nF}$ factorial runs (ensuring possible combinations for the operating parameters with maximum and minimum values), along with the achieved results during every experiment. The values of experimental parameters altered within three levels, between $-1,0$, and +1 (Table 1 ).

Table 1 Actual values with coded values in parenthesis for the experimental parameters

\begin{tabular}{crrr}
\hline Experimental Parameters & \multicolumn{3}{c}{ Actual value (Coded value) } \\
\hline A. Strength of BS Solution & $0.2 \%(-1)$ & $0.6 \%(0)$ & $1 \%(+1)$ \\
B. Steeping Time (hrs) & $4(-1)$ & $6(0)$ & $8(+1)$ \\
C. Mixing Ratio with BS Solution & $1: 1(-1)$ & $1: 1.5(0)$ & $1: 2(+1)$ \\
D. Mixing Ratio with UPW & $1: 0.4(-1)$ & $1: 0.5(0)$ & $1: 0.6(+1)$ \\
\hline
\end{tabular}

This experimental study conducted 30 runs in total following the equation $C C D=2^{k}+2 k+6$, where the number of parameters is k. For attaining the optimum values of strength of BS solution (A), steeping duration (B), mixing ratio with BS solution (C) and mixing ratio with UPW (D), this study analysed the starch yield (\%) (Y) as a dependent parameter with 24 experiments and 6 repetitions (Karimifard and Alavi Moghaddam, 2018). For predicting the optimized experimental conditions, Eq. (1) exhibits the mathematical quadratic equation model (Sabour and Amiri, 2017):

$$
Y=\beta_{0}+\sum_{i=1}^{k} \beta_{i} X_{i}+\sum_{i=1}^{k} \beta_{i i} . X_{i}^{2}+\sum_{i=1}^{k} \sum_{i<j}^{k} \beta_{i j} . X_{i} . X_{j}+\ldots .+\varepsilon
$$

In this equation, the desired response is $\mathrm{Y}, \mathrm{j}$ is the quadratic coefficient, $\mathrm{i}$ is the linear constant, $\mathrm{Xj}$ and $\mathrm{Xi}$ are the parameters, $\mathrm{k}$ indicates the number of operating parameters investigated as well as optimized through this study. $\beta_{0}$ represents the regression coefficient, and $\beta_{\mathrm{i},} \beta_{\mathrm{ii}}, \beta_{\mathrm{ij}}$ are the interacting coefficients for linear, quadratic as well as second-order terms, while $\varepsilon$ indicates the random error.

To attain the interrelationship amid the process parameters as well as the desired response, the Analysis of Variance (ANOVA) conducted the data analysis. This analysis illustrates simultaneously the significance as well as the influence of respective factor over desired responses. The values of coefficient of determination $\left(\mathrm{R}^{2}\right)$ along with adjusted $\mathrm{R}^{2}$ identify the fitting excellence of the polynomial model, while the F- test (Fisher's variation ratio), as well as adequate precision of the similar program evaluates 
the statistical significance of linear and quadratic terms. Predicted $R^{2}$ illustrates the prediction capability of the suggested model through PRESS (predicted residual error sum of squares). P-value (probability) associated with a confidence level of $95 \%$ evaluated the model parameters and their interactions. DesignExpert Software provided finally three-dimensional (3D) response surface and its corresponding contour plots.

\subsection{Physical Characteristics of Oil Palm Trunk Starch (OPTS)}

\subsection{1 pH and Moisture Content of OPTS}

About $1.5 \mathrm{gm}$ of starch was mixed up with $25 \mathrm{ml}$ of purified water in an extraction bottle $(50 \mathrm{ml})$, for determining the $\mathrm{pH}$ according to the previous study (Abd Karim et al., 2020). After proper mixing with a portable shaker for 3 mins, the mixture became stable within 15 min before $\mathrm{pH}$ measurement.

For achieving the moisture content (\%) of oil palm extracted starch, $2 \mathrm{gm}$ of the sample was positioned within a natural convection oven with $105^{\circ} \mathrm{C}$ temperature for $24 \mathrm{hrs}$. After optimum drying in the oven, the starch sample was set in a desiccator for about 15 min to cool down before measuring the moisture content from weight loss. From the initial weight $\left(\mathrm{W}_{1}\right)$ of starch before drying and oven-dried weight $\left(\mathrm{W}_{2}\right)$, moisture content was calculated.

\subsubsection{Particle size and Polydispersity analysis}

After properly dispersing the oil palm trunk starch sample, Malvern Zetasizer version 6.01 attired with Scirocco dry powder feeding device, analysed the particle size distribution, as well as polydispersity index (PDI), which expresses the broadness of molecular weight distribution. Particle size measurement was expressed in terms of the micrometer $(\mu \mathrm{m})$, while PDI is a numerical value only.

\subsubsection{Analysis of Surface Morphology}

The surface morphological structure and elemental analysis with composite homogeneity of oil palm trunk starch were investigated applying digital electron microscopic analysis (SEM) as well as energydispersive X-ray spectroscopy (EDX) using ophthalmic microscope FEI-Quanta 450 FEG. The dispersion of starch was put on the aluminum heel, coated with a lean layer (30 angstroms) of gold (sputtering) through the Polaron SC515 SEM coating system and then fixed on a sample table utilising conductive carbon glue. The analysis was conducted under standard conditions within an expediting voltage of $20 \mathrm{kV}$. 


\subsubsection{X-ray diffraction Analysis (XRD)}

Siemens, Germany provided Kristal-loflex D-5000 X-ray diffraction system performed the X-ray diffraction analysis for dried starch powder comprising around $10.8 \%$ moisture, to detect the proportion of crystal-like arrangement in starch. After dehydration in a desiccator and removing the dust or any contaminants the starch samples were laid on an aluminum specimen stub as densely as possible. Then the X-rays diffraction shape was documented through the operation with monochromatic filter, $\mathrm{Cu} \mathrm{K} \alpha$ radiation $(\lambda=154.0)$ with $40 \mathrm{kV}$ of opening voltage as well as $30 \mathrm{~mA}$ of current. The scanning procedure was undertaken at a $2 \theta$ angle of diffraction within a range of $10^{\circ}$ to $70^{\circ}$ with a varying speed of scanning $(0.02 \% \min$ to $2 \% \mathrm{~min})$.

\subsubsection{FTIR Spectroscopy}

Fourier-transfer infrared (FT-IR) analysis was conducted to determine the existence of organic functional groups in the extracted oil palm trunk starch. Spectrum IR Tracer-100 Series FTIR (Shimadzu, Tokyo, Japan) outfitted through a diamond ATR mechanism performed the FTIR analysis of dried powder like sample of starch (Wu et al., 2020). The ultimate outcome spectrum was acquired from the analysis of at least three spectra for the sample. $1 \mathrm{mg}$ of starch sample was mixed up with $\mathrm{KBr}(100 \mathrm{mg}$, pure spectrum), which was prepared previously through enough grinding and pressed into a pellet suitable for FTIR analysis. FTIR spectroscopic analysis was then conducted and the spectra were in the range of $4000 \mathrm{~cm}^{-1}$ to $400 \mathrm{~cm}^{-1}$. Transmittance peaks were recognized based on published articles for FTIR spectral peaks and understood the variance in the acquired data further through recognising the patterns in the samples (Bolyard et al., 2019).

\subsubsection{Solubility Index (SI) and Swelling Power (SP)}

The solubility index (\%) along with swelling power (SP) of the starch samples was undertaken following the procedure demonstrated by previous researchers (Lai et al., 2016). Certain volume (10 ml) of deionised water was supplemented in the centrifuging bottle after measuring its weight and placing $100 \mathrm{mg}\left(\mathrm{W}_{\text {sa }}\right)$ of the starch sample over there. For more authentication, samples were prepared in triplicate. After 2 mins shaking with a handheld shaker, the centrifuging tubes with suspension were heated in the water bath at an intermission of every $10^{\circ} \mathrm{C}$ within a varying temperature from $50^{\circ} \mathrm{C}$ to $90^{\circ} \mathrm{C}$. Heating, inside water bath, was performed until 35 mins for each varying temperature with a whirl 
mixing at every 5 min intervals. Tubes were centrifuged at $4500 \mathrm{rpm}$ until $35 \mathrm{mins}$ after heating, and the supernatant was placed for oven drying at $105^{\circ} \mathrm{C}$ for up to $24 \mathrm{hrs}$. Once the weight of starch sediments (sticking portion to the tube wall) $\left(\mathrm{W}_{\mathrm{se}}\right)$, as well as dried supernatant $\left(\mathrm{W}_{\mathrm{su}}\right)$ were measured, then water solubility (SI) along with swelling power (SP) were determined according to the following equations (2) and (3).

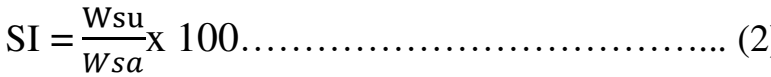

$$
\begin{aligned}
& \mathrm{SP}=\frac{\text { Wse }}{W s a(1-W S)}
\end{aligned}
$$

\section{Results and Discussion}

\subsection{Analysis of Experimental data from RSM}

Response surface methodology (RSM) analysed the impact of experimental parameters, i.e. the strength of BS solution (A), steeping time (B), mixing ratio with BS solution (C) and UPW (D) over the process response starch yield (Y) for the application of bisulfite steeping method.

Table 2 displays the central composite design (CCD) to develop the mathematical model equation applying Analysis of Variance (ANOVA), with corresponding results (Y) evaluated in terms of experimental parameters $(\mathrm{A}, \mathrm{B}, \mathrm{C}, \mathrm{D})$. To relate the experimental variations with predictable random error is the basic concept of ANOVA (Sabour and Amiri, 2017). The properties of the unrestrained parameters were minimised through randomising the experimental sequences. Similarly, Table 2 displays the actual with predicted responses of starch yield concerning the operating parameters. ANOVA analysed the obtained results for assessing the "goodness of fit" of the model. The first equation from ANOVA analysis was modified, while the equation (4) depicts the ultimate quadratic models in terms of coded factors after excluding the insignificant terms. The negative sign in equation shows hostile effect while a positive sign ahead the terms specifies synergistic consequence (Azmi et al., 2015). The equation calculated the parameters as the combination of second order $\left(\mathrm{A}^{2}, \mathrm{~B}^{2}, \mathrm{C}^{2}\right)$, first-order (in terms of $\mathrm{A}, \mathrm{B}$, C), 2 interlinked effects $(\mathrm{AB}, \mathrm{AD})$ with a constant, according to Eq. (1). 
Table 2 Central composite design outcome for experimental parameters and response (actual and predicted)

\begin{tabular}{|c|c|c|c|c|c|c|}
\hline \multirow{2}{*}{ Run } & \multicolumn{4}{|c|}{ Experimental design for process parameters } & \multicolumn{2}{|c|}{ Response (\% Yield) } \\
\hline & A & $\mathrm{B}$ & $\mathrm{C}$ & $\mathrm{D}$ & Actual & Predicted \\
\hline 1 & 1 & 6 & 1 & 0.6 & 11 & 11.34 \\
\hline 2 & 1 & 4 & 1.5 & 0.5 & 12 & 11.13 \\
\hline 3 & 0.6 & 4 & 1.5 & 0.4 & 12.65 & 12.92 \\
\hline 4 & 1 & 2 & 2 & 0.6 & 9.5 & 9.32 \\
\hline 5 & 0.6 & 6 & 1.5 & 0.5 & 12.8 & 13.02 \\
\hline 6 & 0.6 & 4 & 1.5 & 0.5 & 13 & 12.92 \\
\hline 7 & 1 & 6 & 1 & 0.4 & 10.5 & 10.68 \\
\hline 8 & 0.2 & 6 & 2 & 0.6 & 7.35 & 6.69 \\
\hline 9 & 0.6 & 4 & 1.5 & 0.5 & 13 & 12.92 \\
\hline 10 & 0.6 & 4 & 2 & 0.5 & 12.8 & 12.56 \\
\hline 11 & 0.2 & 6 & 2 & 0.4 & 7.2 & 7.35 \\
\hline 12 & 0.6 & 4 & 1.5 & 0.5 & 13 & 12.92 \\
\hline 13 & 0.6 & 4 & 1 & 0.5 & 11.8 & 12.08 \\
\hline 14 & 0.2 & 2 & 2 & 0.4 & 7.45 & 7.35 \\
\hline 15 & 0.6 & 4 & 1.5 & 0.5 & 13 & 12.92 \\
\hline 16 & 0.2 & 2 & 2 & 0.6 & 6.15 & 6.69 \\
\hline 17 & 1 & 2 & 2 & 0.4 & 8 & 8.67 \\
\hline 18 & 1 & 6 & 2 & 0.4 & 11 & 11.15 \\
\hline 19 & 0.6 & 4 & 1.5 & 0.5 & 13 & 12.92 \\
\hline 20 & 0.6 & 4 & 1.5 & 0.5 & 13 & 12.92 \\
\hline 21 & 0.2 & 6 & 1 & 0.6 & 6.65 & 6.22 \\
\hline 22 & 1 & 6 & 2 & 0.6 & 12.15 & 11.81 \\
\hline 23 & 1 & 2 & 1 & 0.6 & 8.5 & 8.85 \\
\hline 24 & 0.6 & 4 & 1.5 & 0.6 & 12.8 & 12.92 \\
\hline 25 & 1 & 2 & 1 & 0.4 & 8.5 & 8.19 \\
\hline 26 & 0.2 & 2 & 1 & 0.4 & 7.5 & 6.88 \\
\hline 27 & 0.2 & 6 & 1 & 0.4 & 6.5 & 6.88 \\
\hline 28 & 0.2 & 4 & 1.5 & 0.5 & 7 & 7.91 \\
\hline 29 & 0.2 & 2 & 1 & 0.6 & 6.4 & 6.22 \\
\hline 30 & 0.6 & 2 & 1.5 & 0.5 & 11.95 & 11.77 \\
\hline
\end{tabular}

The second-order effects in this equation show a negative impact on the starch yield.

Ultimate Model Equation Concerning Coded Factors:

$\%$ Yield $(\mathrm{Y})=12.92+1.61 \mathrm{~A}+0.62 \mathrm{~B}+0.24 \mathrm{C}-3.40 \mathrm{~A}^{2}-0.53 \mathrm{~B}^{2}-0.60 \mathrm{C}^{2}+0.62 \mathrm{AB}+0.33 \mathrm{AD}$ 
Table 3 shows the consolidated results of analytical parameters in accordance with ANOVA. Analytical Data displaying in the mentioned table indicate that at the $95 \%$ confidence level the models are significant since $\mathrm{P}$ values are less than 0.0001 .

Table 3 ANOVA Outcome for Modified Quadratic Model of Response Surface

\begin{tabular}{cccccc}
\hline Source & $\begin{array}{c}\text { Sum of } \\
\text { Squares }\end{array}$ & DF & $\begin{array}{c}\text { Mean } \\
\text { Square }\end{array}$ & $\begin{array}{c}\text { F } \\
\text { Value }\end{array}$ & P \\
\hline Regression Model & 193.4 & 8 & 24.17 & 114.91 & 0.0001 \\
Residual & 4.42 & 21 & 0.21 & & \\
Lack of Fit & 4.42 & 16 & 0.28 & & \\
\hline
\end{tabular}

Standard Dev. = 0.46; $\mathrm{R}^{2}=0.98 ;$ Adjusted $\mathrm{R}^{2}=0.967$; Predicted $\mathrm{R}^{2}=0.94 ;$ Adeq. Precision $=27.053$;

\section{Coefficient of Variation $=4.49 ;$ PRESS $=11.73$}

The coefficient of determination along with adjusted $\mathrm{R}^{2}$ assessed the model's capability in the fitting. Meanwhile, predicted $\mathrm{R}^{2}$ and adequate precision specify the prediction capability of the model. The lack of fit (LOF) term is non-significant in fact, while F-test defines the data discrepancy around the fitted model and indicates the significance of regression. Table 3 represents the value of LOF (4.42) and PRESS (11.73) which specifies the sum of squares of prediction error.

The coefficient of determination $\left(\mathrm{R}^{2}\right)$ provides the total portion of the model predicted response variation, representing the proportion of the regression sum of squares (SSR) to the overall sum of squares (SST). The greater values of $\mathrm{R}^{2}(0.95-0.98)$, as well as adjusted $\mathrm{R}^{2}(0.91-0.97)$ are appropriate and the indicator of the satisfactory adaptation between experimental results with the obtained quadratic model. Moreover, a sensible correspondence among the $\mathrm{R}^{2}$ and adjusted $\mathrm{R}^{2}$ (closeness in values) is essential, since it designates the lower impact of $\mathrm{R}^{2}$ enhancement because of the insertion of insignificant variables (Sharifi, Zabihzadeh and Ghorbani, 2018). The values of the coefficient of determination (0.98) and adjusted $\mathrm{R}^{2}(0.967)$ in this study (Table 3 ) strongly reveal the significance of the model according to the statistical rules mentioned above.

Predicted $\mathrm{R}^{2}$ and adequate precision (AP) illustrate the prediction capability of the models, while adequate precision (AP) relates the sequence of the projected values to its average standard error. AP is indeed a sort of signal-noise fraction, and its value should be 4 or above to ensure an appropriate 
calculation for a model. Once, the value for AP remains between 15.0 to 30 confirming the firm prediction aptitude of the models. Conceptually predicted $\mathrm{R}^{2}$ could be evaluated after modification from the remaining values of a regression model and it reflects the success of prediction from excluded values and residual sum of squares (Myers H Raymond and Cook, 2016). The predicted $\mathrm{R}^{2}$ value, which ranges from 0.8 to 0.92 , reveals a strong model prediction. The values of predicted $\mathrm{R}^{2}(0.94)$ and AP (27.053) of the achieved model (Table 3) are firmly in agreement that this model can traverse the design space illustrated by central composite design.

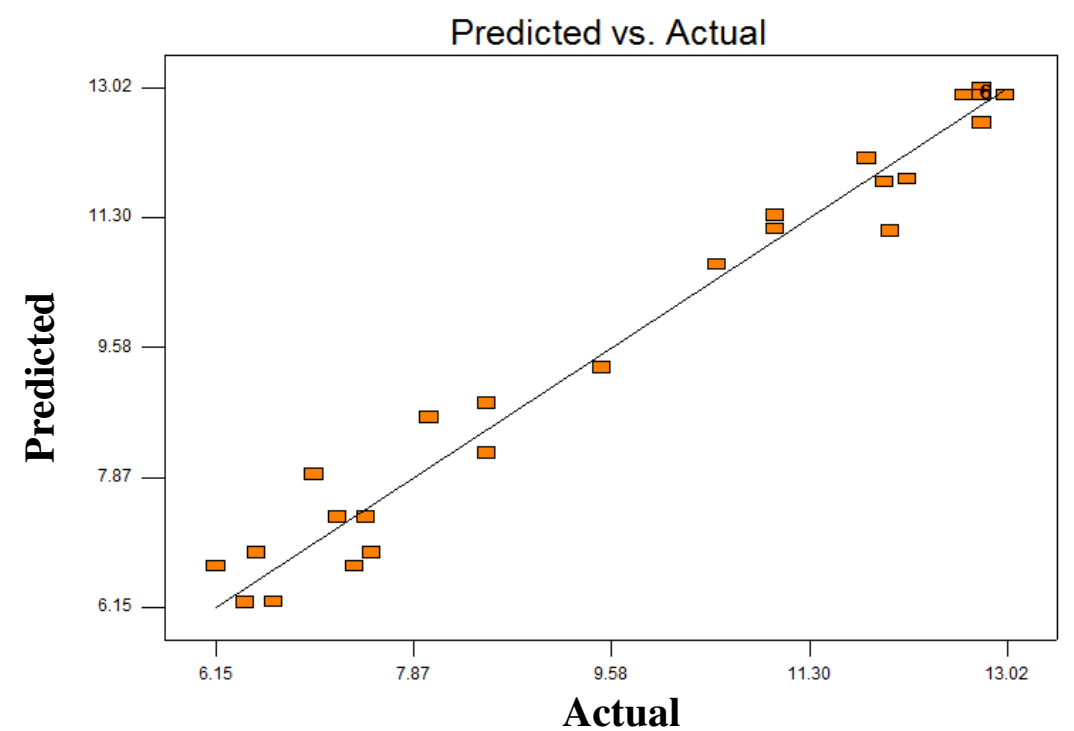

(a)

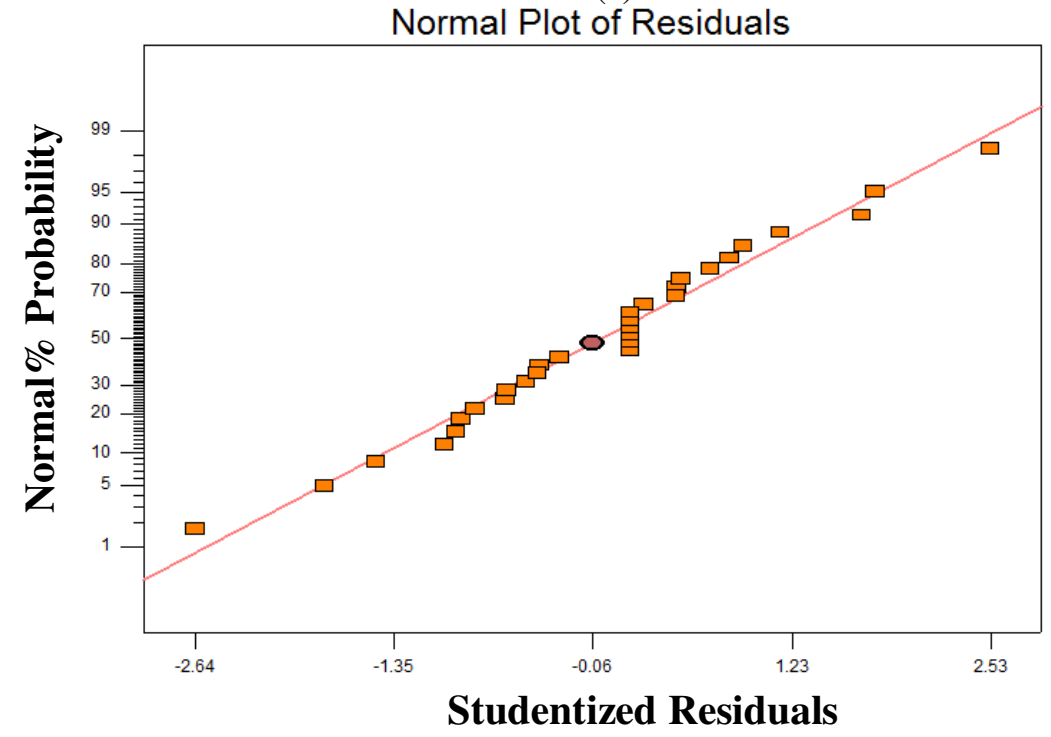

(b)

Fig. 3 Design Expert originated plot (a) actual vs predicted; (b) Normal probability plot of the residuals 
The coefficient of variation (CV) is the most potent method for determining the validity of a sample, which specifies the proportion of the expected standard error to the mean value of the practical response. A model's CV value no more than $10 \%$ (5.86\% to $10.66 \%$ more precisely) is more consistent because the lower CV values, the closer the predicted values are (Ghani et al., 2017). The obtained model may be designated as reproducible concerning the value of CV (4.49), following Table 3.

ANOVA diagnostic plots showing the correlation between actual experimental values and predicted values guide us to justify the model competence. Figure 3 displays the scattering amid the data points for predicted against actual values of the starch yield obtained by the model, and the diagonal line presented satisfactory agreement.

\subsection{Process analysis}

Figure $4(\mathrm{a}, \mathrm{b}, \mathrm{c}, \mathrm{d})$ displays the 3D response surface plots for starch yield based on ANOVA and numerical optimization correspondingly. The plots displaying in figures are almost well-proportioned in outline with round contours. The response surface figures exhibit very strong peaks, signifying the optimal operating conditions for the highest response (starch yield) value regarding the experimental parameters in the design space.

RSM generated 3D response surface plots as shown in Fig. 4(a), 4(b) displays the consequences of interaction amid the strength of BS solution, and steeping duration. It is quite evident that the starch yield increases with the enhancement of these parameters up to a certain level. This might be because of the activating of BS solution at room temperature, which interacts and accelerates the process of breakdown of chemical bond within the substantial steeping duration inside biomass. The breakdown process is also recognized as the reaction of elimination (Azmi et al., 2015). Response surface plots in Fig. 4, designate the optimal points to be $0.74 \%$ BS solution, $5.60 \mathrm{hrs}$ steeping duration, with mixing ratio 1:1.60, 1:0.6 for BS solution as well as UPW respectively for highest starch yield. Moreover, 3D response surface plots (Fig. $4 \mathrm{c}, 4 \mathrm{~d}$ ) also reveal that the response (starch yield) depicts a reduction for increasing or decreasing the values of tested parameters. 


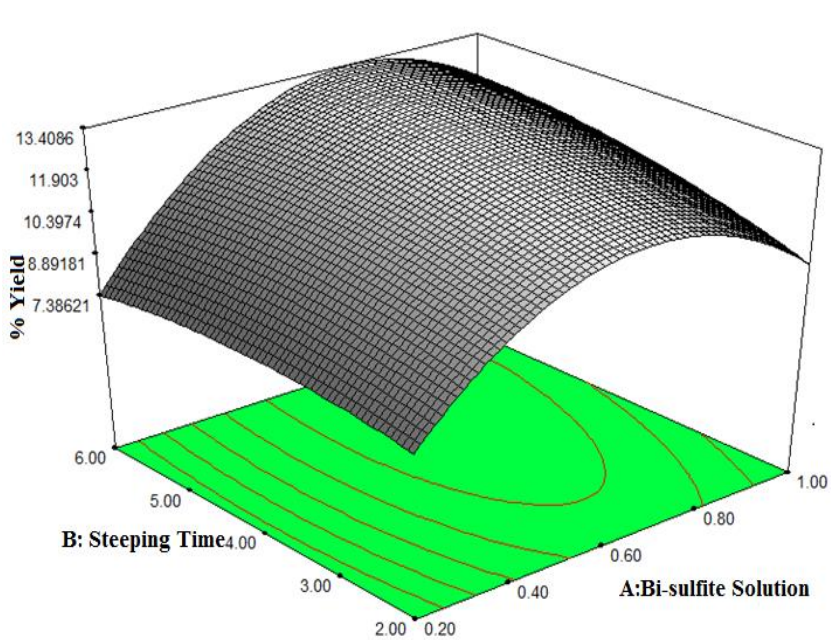

(a)

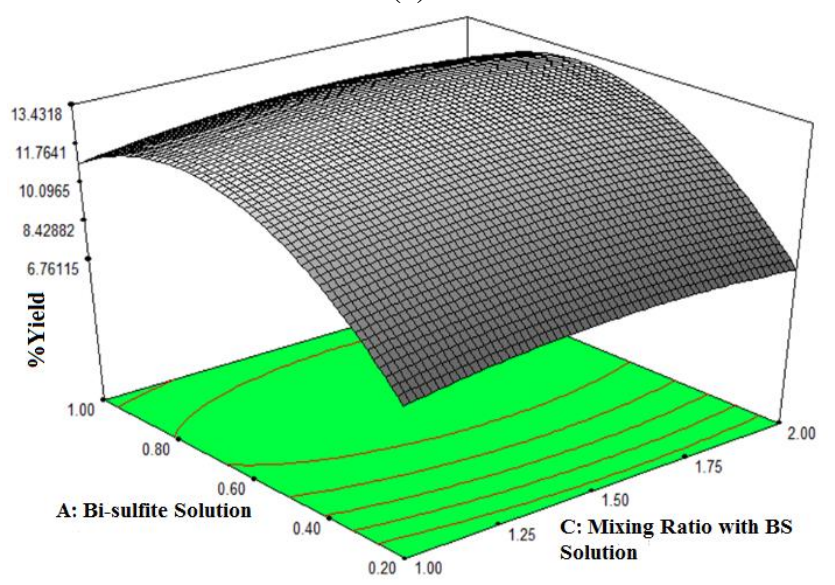

(c)

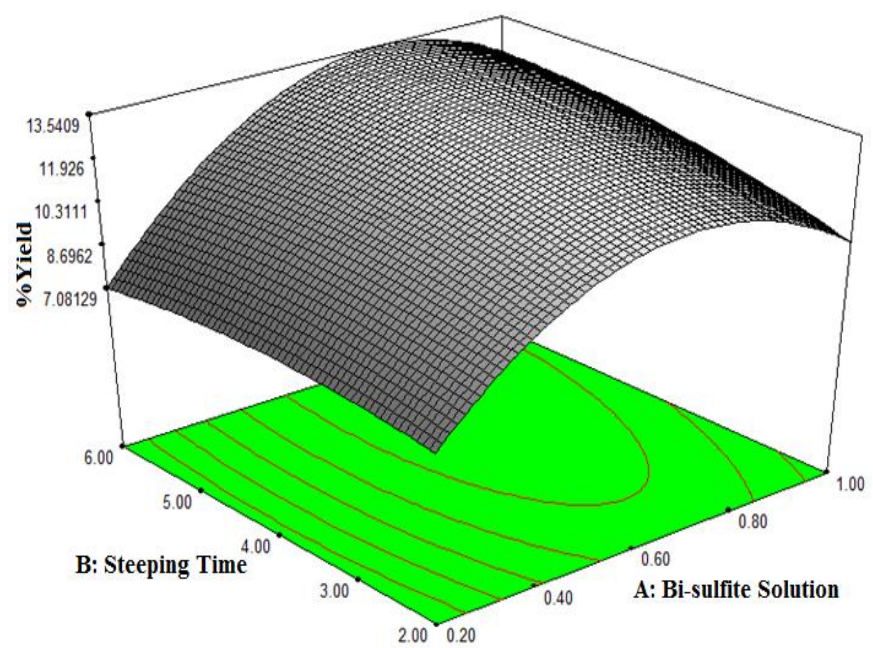

(b)

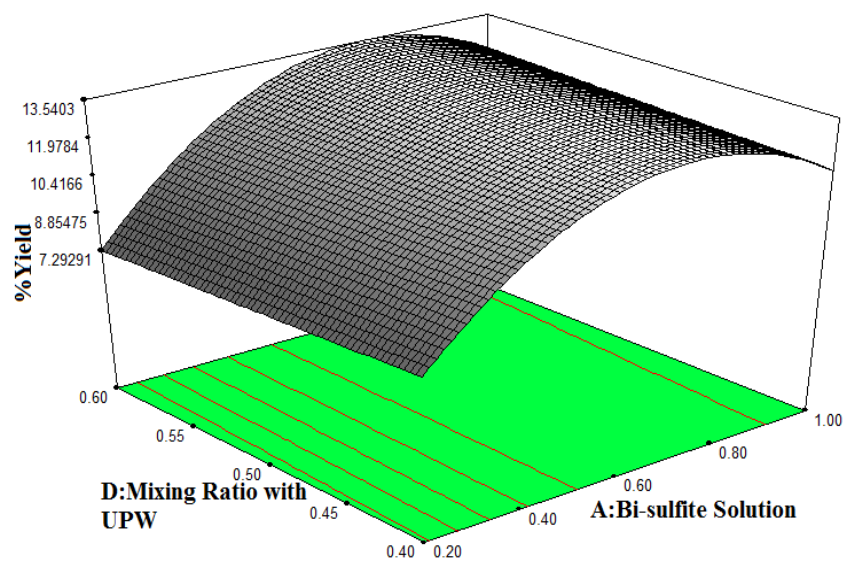

(d)

Fig. 4 3D Response Surface Plot, (a) model graph from ANOVA; (b), (c), (d) numerical Optimization based on interrelation of parameters;

Maintaining a constant value for the strength of BS solution and steeping time according to the optimization solution, change in the values of both mixing ratios showed a decline in starch yield. In Fig. $4 \mathrm{~b}$ the response surfaces exhibit $13.54 \%$ starch yield at the optimized condition for applying this bisulfite steeping method which is remarkably higher than previous studies.

\subsection{Process optimization}

Design master programming (Fig. 5) of Design-Expert software assessed the standard situations for ensuring maximum yield of starch where all parameters coincidentally address the necessary criteria concerning higher and lower limits, associating the quality capacity (Kumar Gupta et al, 2017). The preferred response limit was from $7 \%$ to $14 \%$, which is comparatively adjacent to the attained value. The goal was to maximise the yield in terms of the lowest allowable values of the experimental parameters to 
obtain a reasonably specific optimum zone. The achieved outcomes are consistent with the operating parameters, which lead to the ideal conditions for starch yield measurement.

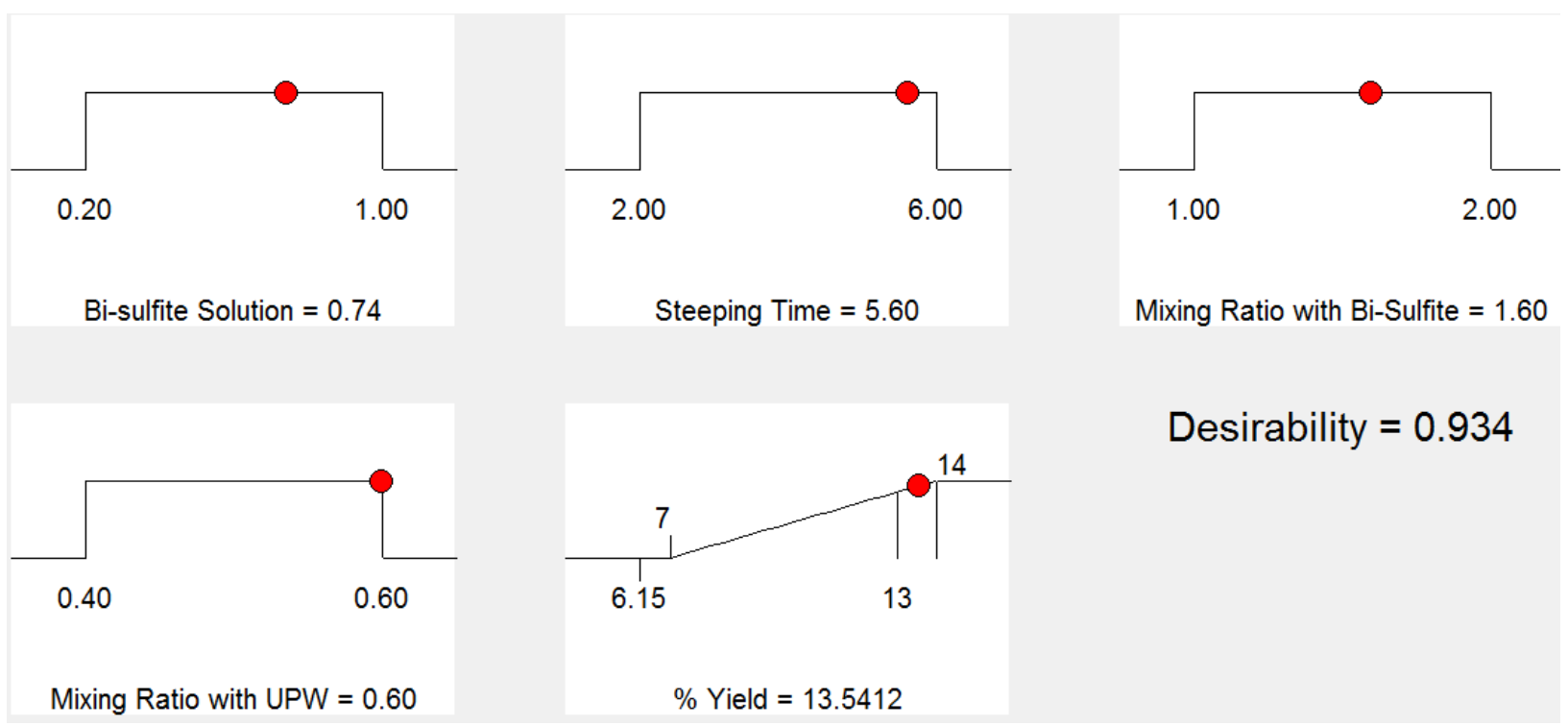

Fig. 5 Desirability ramp for numerical optimization for four parameters and one response

The highest starch yield observed with this condition was $13.54 \%$, with desirability function 0.934 , and these conditions were reviewed at room temperature under the corresponding setting up. To verify the proposed optimum condition, three additional experiments were performed following the same values of the testing parameters to authorise the predicted agreement of the models. Based on the outcomes of the verification study, the average starch yield extracted $13.54+0.4 \pm 0.3 \%$, which is quite a satisfactory agreement from the regression model, with a comparatively lower error of $2.95 \%$.

However, the outcomes of the experiments confirmed the model soundness satisfactorily, ensuring the existence of the optimal point, and at the same time, recognise the significance of this method for increasing the starch yield successfully.

\subsection{Outcomes of Physical Characteristics of Starch}

\subsubsection{Starch Yield from Oil Palm Trunk}

According to the central composite design (CCD) batch experimental outcomes showed that this bisulfite steeping method could ensure maximum starch yield 13\% at $0.6 \%$ BS solution, 4 hrs steeping duration with the mixing ratio of 1:1.5, and 1:0.5 for BS solution as well as ultra-pure water respectively. Although extracting the starch from the cells of the abrasive vascular bundles of oil palm trunk is quite hard, rather this combination of proposed method augmented the yield remarkably higher than the yield 
demonstrated by previous researchers regarding starch extraction from oil palm trunk (Abd Karim et al., 2020), sago trunk (Aziz and Sobri, 2015) and cassava peel or potatoes (Waterschoot et al., 2015). Furthermore, it was also observed that the changes in the experimental parameters reduce the starch yield. Besides this, extracted OPTS showed off white wheat brown color because of the presence of enzymatic phenolic compounds that produce polyphenolic pigments through some chemical reactions (Lattanzio, Cardinali and Linsalata, 2012).

\subsection{2 pH and Moisture Content}

The nature of extracted starch found acidic since the measured $\mathrm{pH}$ value was 4.86 , which is also almost similar to the earlier research outcomes (Abd Karim et al., 2020).

The value of the moisture content of the extracted starch found $10.74 \%$, which is very much consistent with the previous outcomes (Abd Karim et al., 2020) for starch extraction from OPT. According to the scientific report, moisture content of starch normally remains from 9\% to 15\% (Zhu and Guo, 2017). For more authentication, this study tested the samples in triplicate.

\subsubsection{Particle size and Polydispersity Index}

Malvern Zetasizer test confirmed the Z-average hydrodynamic particle size distribution of extracted starch in this study is about $7.152 \mu \mathrm{m}$ while the normal range of granular starch size is $3 \mu \mathrm{m}$ to $25 \mu \mathrm{m}$. OPTS particles showed a bimodal distribution of granular size as explained by the previous researchers, which is also similar to the other cereal starches like wheat, and barley (Gilbert et al., 2010) but the granule size of sago starch $(15-50 \mu \mathrm{m})$ is higher than oil palm trunk starch (Aziz and Sobri, 2015). Starch granular deformation is responsible for the reduction of its molecular weight significantly. The average molecular weight of OPTS is approximately $865 \mathrm{kDa}$ according to the testing outcome. The molecular weight of OPTS indicates it's as a high molecular weight (greater than $100 \mathrm{kDa}$ ) polymer (Zamri, Mohd Akhiar and Halim Shamsuddin, 2019).

The polydispersity index (PDI) of polymer is another significant term that indicates the broadness of its molecular weight distribution. According to the Zetasizer test, the PDI of OPTS verified that OPTS suspensions are monodisperse and uniform since the value is comparatively higher $(0.869)$. The high value of PDI of OPTS also confirms the existence of impurities fragments, as well as oligomeric 
assemblies in OPTS. However, IUPAC ideally considered OPTS as a uniform polymer rather than a monodisperse polymer.

\subsubsection{SEM-EDX Investigations Outcomes}

OPTS granule morphology was scrutinised using Scanning Electron Microscopy (SEM) and Fig. 6 (a, b) shows the achieved images of oil palm trunk starch (OPTS) at 4000 and 6000 magnifications from SEM analysis, while Fig. 6 (c) represents the EDX analysis result of oil palm trunk starch. OPTS granules considered much greater granular sizes, i.e. 10-100 diameter $\mu \mathrm{m}$. This phenomenon was coherent with other OPTS granular architecture characteristics, featuring a much mature or possibly fully mature storage starch. The micrographs show that the granular architecture of OPTS is almost like sago palm starch, representing ovular and elliptical patterns with condensed ends. Bell-shaped granules were also observed. This outcome was almost similar to the explanations by Hashim et al. (Nadhari et al., 2013). Furthermore, from the apparent particle fractions, a minor fraction of OPTS particles represented hourglass structure along with almost areolate shape including several trumpet-like swellings. On the other hand, OPTS granule surface seemed a little bit less smooth than previous studies and marked by more wave-like creases. Simultaneously SEM outcomes unveiled the presence of radial pattern surface openings as well as some grooves or hollows on large-sized OPTS granule, which is not available in early researches. The conspicuous openings of 0.5-2.0 $\mu \mathrm{m}$ diameters, could be openings to channels that stabbed over various rings of starch growing as well as the hilum, while a portion remained on the outer layer only.

Figure 6 (c) displayed the presence of several minerals i.e. $\mathrm{Na}, \mathrm{K}, \mathrm{Mg}$, with carbon $(\mathrm{C})$ and oxygen (O) in oil palm trunk starch according to the Energy Dispersive X-Ray Analysis (EDX) analysis. Ample existence of oxygen has followed in OPTS due to the lavish combination of carbohydrate (Aziz and Sobri, 2015). Furthermore, carbohydrates are broken down in form of energy through using oxygen. 


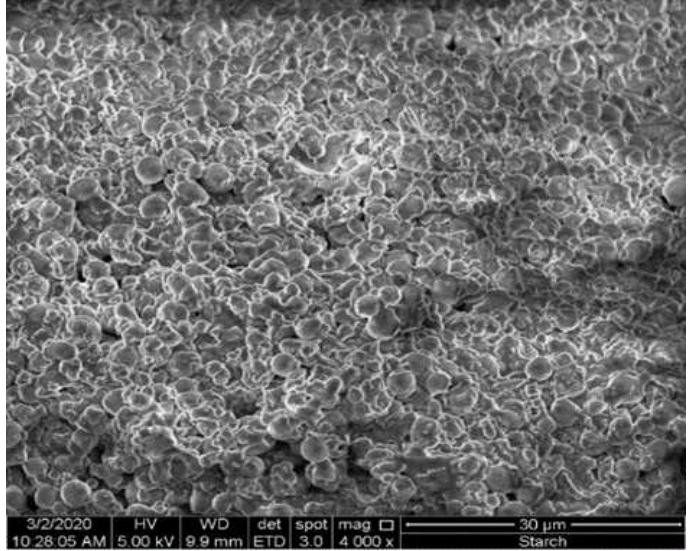

(a)

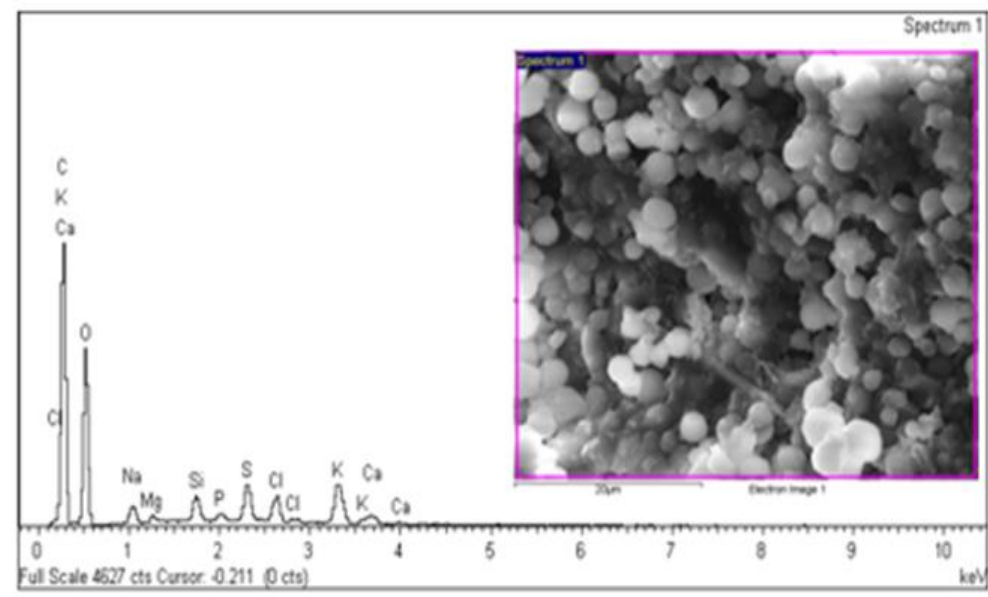

(c)

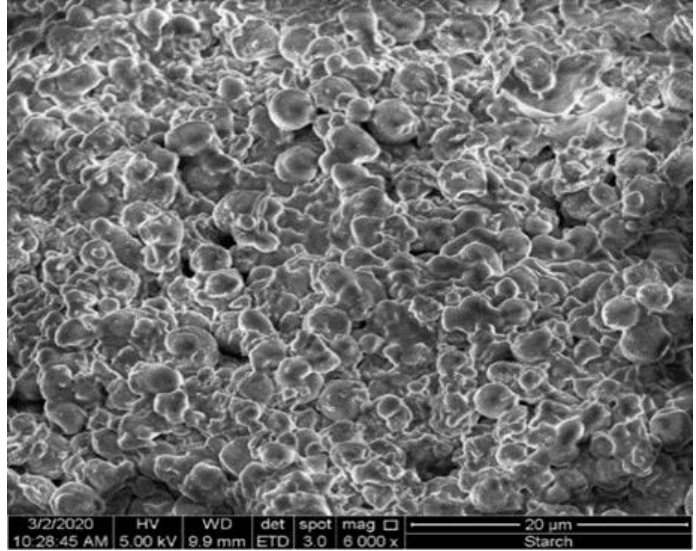

(b)

\begin{tabular}{|c|c|c|}
\hline Elements & Weight(\%) & Atomic(\%) \\
\hline $\mathrm{C} \mathrm{K}$ & 55.83 & 64.62 \\
\hline $\mathrm{O} \mathrm{K}$ & 37.3 & 32.42 \\
\hline $\mathrm{Na} \mathrm{K}$ & 0.8 & 0.48 \\
\hline $\mathrm{Mg} \mathrm{K}$ & 0.21 & 0.12 \\
\hline $\mathrm{Si} \mathrm{K}$ & 0.77 & 0.38 \\
\hline $\mathrm{P} \mathrm{K}$ & 0.28 & 0.13 \\
\hline $\mathrm{S} \mathrm{K}$ & 1.38 & 0.6 \\
\hline $\mathrm{ClK}$ & 1.13 & 0.44 \\
\hline $\mathrm{K} \mathrm{K}$ & 1.89 & 0.67 \\
\hline $\mathrm{Ca} \mathrm{K}$ & 0.42 & 0.15 \\
\hline Totals & 100 & \\
\hline
\end{tabular}

Fig. 6(a) SEM micrograph of native starch at 4000 magnification; 7(b) SEM micrograph of native starch at 6000 magnification; 7(c) EDX analysis report for OPTS

\subsubsection{XRD Analysis of Oil Palm Trunk Starch}

X-ray diffraction analytical outcome (Fig.7) of oil palm trunk powdered starch samples shows the peaks of strong intensity at $2 \theta$ values (Bragg angles) of approximately $22.5^{\circ}$ according to its crystalline arrangement, while secondary peaks are observed at $2 \theta=14.75^{\circ}$ and $2 \theta=21.7^{\circ}$ exhibiting diffraction pattern nearer to A-type crystallinity pattern, which eventually declare its similarity with other representative A-type starches such as cereals. Rather, relating with extracted OPTS by Noor et al. (1999), in the current study OPTS displayed significant structural disruption of typical A-type crystallinity, probably because of the granular disintegration during starch crushing. The peaks, for the intensity of the amorphous portion were observed at $2 \theta=19.25^{\circ}$. The crystallinity index of OPTS was $28.5 \%$, which remains in the range of the relative crystallinity standard of $15-48 \%$ for common native starch, while the lower crystallinity of OPTS indicates the presence of higher amylose (Qin et al., 2016). 


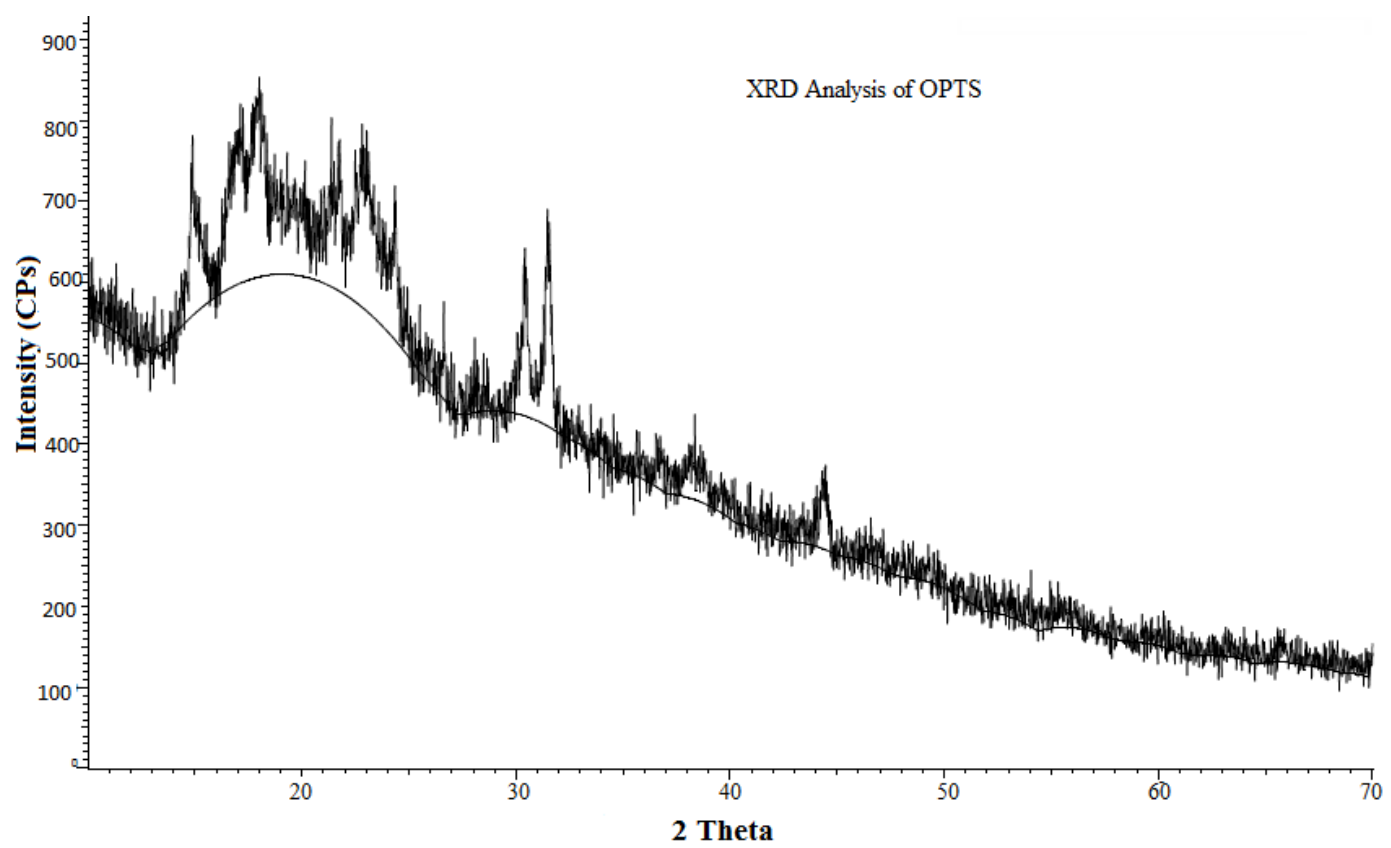

Fig. 7 XRD analytical shape of OPTS

\subsubsection{FTIR Spectrum Analysis Outcomes}

Figure 8 displays the FT-IR spectra of the extracted oil palm trunk starch. The band shape of OPTS is quite consistent with the exclusive spectral pattern of starch. The outcome exhibits significant peaks in the starch impression zone $\left(970-1200 \mathrm{~cm}^{-1}\right)$ at $1020 \mathrm{~cm}^{-1}, 1083 \mathrm{~cm}^{-1}$, and $1153 \mathrm{~cm}^{-1}$, which overlays the C-O stretching in C-O-H side group (Ghosh Dastidar and Netravali, 2012). The spectrum indicates the presence of effective groups like hydroxyl, carbonyl, carboxyl, methoxy groups as well as amino (amine and amide) in OPTS. Peaks at $2858 \mathrm{~cm}^{-1}, 2926 \mathrm{~cm}^{-1}$, and $3358 \mathrm{~cm}^{-1}$ represented the hydroxyl (O-H) active group, which commonly available in carboxylic acids, phenols, or alcohols (Moharrami and Motamedi, 2020). A band at $1635 \mathrm{~cm}^{-1}$ represents the structural vibration of aromatic double bonds $\mathrm{C}=\mathrm{C}$ (Ferraz et al., 2016). Peak appearances at $1411 \mathrm{~cm}^{-1}$ and $1452 \mathrm{~cm}^{-1}$ attribute the presence of aromatic groups (C-C stretch, strong) (Moharrami and Motamedi, 2020) and alkanes group (C-H-C bend) while another peak $1242 \mathrm{~cm}^{-1}$ represents strong C-N stretching. Functional group amines in OPTS displayed the peaks traceable to $\mathrm{N}-\mathrm{H}$ wagging $\left(709 \mathrm{~cm}^{-1}, 767 \mathrm{~cm}^{-1}\right.$, and $\left.860 \mathrm{~cm}^{-1}\right)$, at the same time the peaks at 530 $\mathrm{cm}^{-1}, 578 \mathrm{~cm}^{-1}$, and $615 \mathrm{~cm}^{-1}$ reveal the presence of alkyl halides $(\mathrm{C}-\mathrm{Br}$ stretch). 


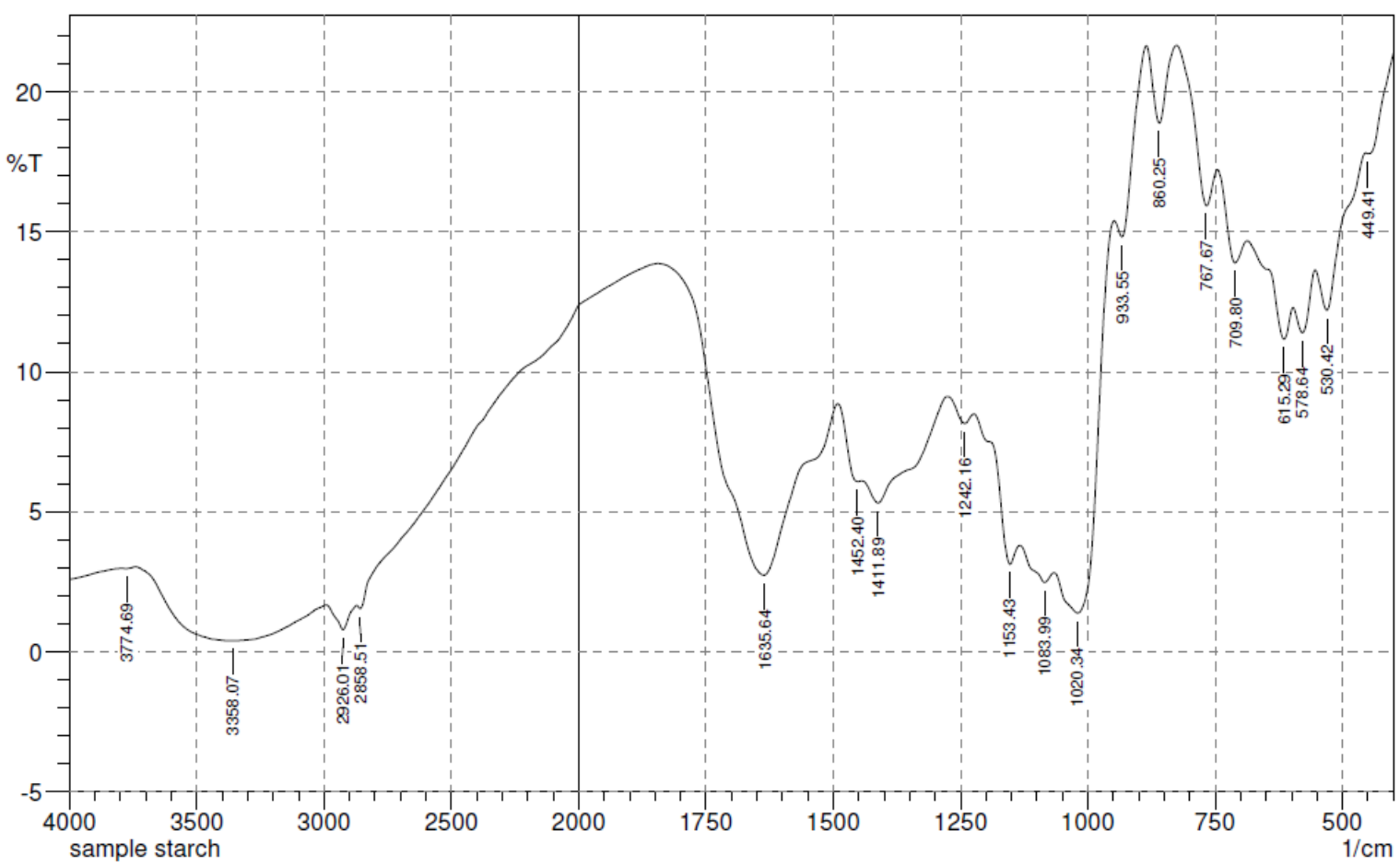

Fig. 8 FTIR spectrum for extracted starch (OPTS)

Moreover, the peaks at $1242 \mathrm{~cm}^{-1}, 1153 \mathrm{~cm}^{-1}, 1083 \mathrm{~cm}^{-1}$, and $1020 \mathrm{~cm}^{-1}$ indicate the existence of esters and carboxylic acids (C-O stretching), which is comparable with polysaccharides. In brief, all these outcomes of FTIR analysis eventually declare the success of starch extraction from oil palm trunk through this study.

\subsubsection{Swelling power (SP) and Solubility Index (SI)}

Table 4 displays the water solubility index (SI) as well as swelling power (SP) of oil palm trunk starch upon 5 dissimilar temperatures from $50^{\circ} \mathrm{C}$ to $90^{\circ} \mathrm{C}$ at $10^{\circ} \mathrm{C}$ interval. Swelling power and solubility index is the evidence of internal action of the amorphous as well as crystalline areas (Abd Karim et al., 2020) but, there is no straight relationship among these properties. In addition, amylose, amylopectin characteristics, and bond strength among the molecules also influential over these properties (Kusumayanti, Handayani and Santosa, 2015). The outcomes revealed a steady augmentation in swelling power until the temperature reached $75^{\circ} \mathrm{C}$. Oil palm trunk starch indicates the maximum swelling power as well as solubility at $72^{\circ} \mathrm{C}$ and $60^{\circ} \mathrm{C}$ respectively. The solubility values vary from $2.89 \%$ to $19.05 \%$, while the swelling power values remain in the range of 2.52 to $6.9(\mathrm{~g} / \mathrm{g})$. The smaller value of the swelling power of oil palm trunk starch denotes the existence of greater amylose content in comparison with other starches, as well as a higher degree of intermolecular relationship. 
Table 4 Solubility Index (SI) and Swelling Power (SP) of Extracted Starch

\begin{tabular}{ccc}
\hline Temperature $\left({ }^{\circ} \mathrm{C}\right)$ & Swelling Power $(\mathrm{SP})(\mathrm{g} / \mathrm{g})$ & Solubility Index $(\mathrm{SI})(\%)$ \\
\hline 50 & 2.52 & 17.17 \\
60 & 2.78 & 19.05 \\
70 & 6.9 & 7.46 \\
80 & 6.53 & 5.23 \\
90 & 5.19 & 2.89 \\
\hline
\end{tabular}

\section{Conclusion}

This study has confirmed the significance of the novel bisulfite steeping method exploiting response surface methodology (RSM), to enhance the natural starch extraction from oil palm trunk biomass. Experimental outcomes defined, that optimum treatment condition of $0.74 \%$ bisulfite solution, $5.60 \mathrm{hrs}$ steeping duration with the mixing ratio of 1:1.6 and 1:0.6 for BS solution and UPW respectively can maximize the yield (13.54\%) at the desirability function of 0.934 . The yield is remarkably higher than the identical method described by Noor et al, (7.15\% yield) (Mohd. Noor et al., 1999) and a bit lower than Sulaiman et al, (around 17\%) (Sulaiman et al., 2013). But both methods used metabisulfite whereas, the current study implemented the bisulfite method and a much less time than Sulaiman et al. The correlation investigation identified the significance of the process mechanisms to optimize the starch yield. A high value of the coefficient of determination $\left(R^{2}=0.98\right)$, as well as adjusted $R^{2}(0.97)$, along with a nearer value of predicted $\mathrm{R}^{2}(0.93)$ confirmed the significance of the developed model based on experimental design. Starch particles were found with high molecular weight $(865 \mathrm{kDa})$ and monodispersed according to the polydispersity index (0.869). Moreover, starch granules indicated the existence of high amylose content with a comparatively low crystallinity index (28.5\%) and A-type pattern. Subsequently, it is also very vital to study various properties (physicochemical, structural, pasting, and rheological) of this natural starch with their relationships, concerning to boost up its applications to a large extent. 


\section{List of abbreviations}

ANOVA- Analysis of Variance

BS- Bisulfite

CCD- Central Composite Design

FTIR- Fourier Transform Infra-Red

OPT- Oil Palm Trunk

OPTS- Oil Palm Trunk Starch

RSM- Response Surface Methodology

SDG- Sustainable Development Goal

SEM- Scanning Electron Microscopy

SP-Swelling Power

SI-Solubility Index

UPW- Ultra Pure Water

\section{Declarations}

Ethics approval and consent to participate

* Not applicable

\section{Consent for publication}

Not applicable

Availability of data and materials

* The datasets used and/or analysed during the current study are available from the corresponding author on reasonable request.

\section{Competing interests}

The authors declare that they have no known competing financial interests or personal relationships that could have appeared to influence the work reported in this paper. 


\section{Funding}

* Funding source of this study was Ministry of Higher Education, Malaysia through "Fundamental Research Grant Scheme (FRGS)" under School of Civil Engineering, University Sains Malaysia.

\section{Authors' contributions}

Zaber Ahmed: Conceptualization, Methodology, Writing- Original draft preparation, Software, Validation and Analysis

Prof. Dr. Mohd. Suffian Yusoff: Reviewing and Editing, Supervision, Funding acquisition

Dr. Nurul Hana Mokhtar Kamal: Reviewing.

Prof. Dr. Hamidi A. Aziz: Reviewing and Editing

\section{Acknowledgements}

The authors would like to convey their warm gratitude to the Ministry of Higher Education, Malaysia for financing this research study through "Fundamental Research Grant Scheme (FRGS)" No- 203/PAWAM/6071415 and School of Civil Engineering, University Sains Malaysia.

\section{Authors' information (optional)}

Mr. Zaber Ahmed: PhD researcher under School of Civil Engineering, University Sains Malaysia with 12 years of academic experiences. He has completed his M.Sc. Engg. Degree and currently holding the position of Assistant Professor, Department of Civil Engineering, Model Institute of Science and Technology, Bangladesh.

Prof. Dr. Mohd. Suffian Yusoff: Professor in Environmental Engineering, School of Civil Engineering, and Deputy Head, Solid Waste Management Cluster, University Sains Malaysia with about 30 years' experience in research and academic field of Environmental Engineering and relevant issues, Solid waste management and Wastewater treatment. Prof. Dr. Mohd. Suffian Yusoff completed B.Sc in Agril Science from UPM, Malaysia while achieved M.Sc and $\mathrm{PhD}$ degree from University Sains Malaysia (USM). 
Dr. Nurul Hana Mokhtar Kamal: Lecturer in Environmental Engineering, School of Civil Engineering, University Sains Malaysia. Dr. Nurul Hana achieved B.Sc and M.Sc Engg degree from UTM Malaysia while pursued PhD from Imperial College of Engineering, UK.

Prof. Dr. Hamidi A. Aziz: Professor in Environmental Engineering, School of Civil Engineering, and Head, Solid Waste Management Cluster, University Sains Malaysia with more than 30 years' experiences in research and academic field of Environmental Engineering and relevant issues, Solid waste management and Wastewater treatment. Prof. Dr. Hamidi achieved B.Sc. Engg., M.Sc. Engg., and PhD in Civil Engineering from United Kingdom.

\section{References}

Abd Karim, N. et al. (2020) 'Properties of native and blended oil palm starch with nano-silicon dioxide as binder for particleboard', Journal of Building Engineering, 29(101151), pp. 1-8. doi: 10.1016/j.jobe.2019.101151.

Abdullah, C. K. et al. (2012) 'Oil Palm Trunk Polymer Composite: Morphology, Water Absorption, and Thickness Swelling Behaviours’, BioResources, 7(3), pp. 2948-2959.

Ahmed, M., Guo, X. and Zhao, X. M. (2016) 'Determination and analysis of trace metals and surfactant in air particulate matter during biomass burning haze episode in Malaysia', Atmospheric Environment. Elsevier Ltd, 141, pp. 219-229. doi: 10.1016/j.atmosenv.2016.06.066.

APHA (2012) Standard methods for the examination of water and wastewater, American Public Health Association, Washington DC.

Aziz, H. A. and Sobri, N. I. M. (2015) 'Extraction and application of starch-based coagulants from sago trunk for semi-aerobic landfill leachate treatment', Environmental Science and Pollution Research, 22(21), pp. 16943-16950. doi: 10.1007/s11356-015-4895-7.

Azmi, N. B. et al. (2015) 'Stabilized landfill leachate treatment by sugarcane bagasse derived activated carbon for removal of color, COD and NH3-N - Optimization of preparation conditions by RSM', Journal of Environmental Chemical Engineering. Elsevier B.V., 3(2), pp. 1287-1294. doi: 10.1016/j.jece.2014.12.002.

Bolyard, S. C. et al. (2019) 'Impact of organic matter from leachate discharged to wastewater treatment plants on effluent quality and UV disinfection', Waste Management. Elsevier Ltd, 88, pp. 257-267. doi: 10.1016/j.wasman.2019.03.036.

Dalton, O. S., Mohamed, A. F. and Chikere, A. O. (2017) 'Status Evaluation of Palm Oil Waste Management Sustainability in Malaysia', OIDA International Journal of Sustainable Development, 10(12), pp. 41-48. Available at: Status Evaluation of Palm Oil Waste Management Sustainability in Malaysia.

Ferraz, F. M. et al. (2016) 'Leachate/domestic wastewater aerobic co-treatment: A pilot-scale study using multivariate analysis', Journal of Environmental Management. doi: 10.1016/j.jenvman.2015.10.034.

Ghani, Z. A. et al. (2017) 'Optimization of preparation conditions for activated carbon from banana pseudo-stem using response surface methodology on removal of color and COD from landfill leachate', Waste Management. Elsevier Ltd, 62, pp. 177-187. doi: 10.1016/j.wasman.2017.02.026.

Ghosh Dastidar, T. and Netravali, A. N. (2012) “"Green” crosslinking of native starches with malonic acid and their properties', Carbohydrate Polymers. Elsevier, 90(4), pp. 1620-1628. doi: 
10.1016/j.carbpol.2012.07.041.

Gilbert, R. G. et al. (2010) Characterizing the Size and Molecular Weight Distribution of Starch: Why It Is Important and Why It Is Hard. doi: 10.1094/CFW-55-3-0139.

H'ng, P. S. et al. (2011) 'OPT as a Resource of Starch and Other Sugars', Journal of Applied Sciences, 11(16), pp. 3053-3057.

Hamzah, N., Tokimatsu, K. and Yoshikawa, K. (2019) 'Solid fuel from oil palm biomass residues and municipal solid waste by hydrothermal treatment for electrical power generation in Malaysia: A review', Sustainability (Switzerland), 11(4), pp. 1-23. doi: 10.3390/su11041060.

Karimifard, S. and Alavi Moghaddam, M. R. (2018) 'Application of response surface methodology in physicochemical removal of dyes from wastewater: A critical review', Science of the Total Environment. Elsevier B.V., 640-641, pp. 772-797. doi: 10.1016/j.scitotenv.2018.05.355.

Kumar Gupta et al (2017) 'Application of response surface methodology to optimize the adsorption performance of a magnetic graphene oxide nanocomposite adsorbent for removal of methadone from the environment', Journal of Colloid and Interface Science. Elsevier Inc., 497, pp. 193-200. doi: 10.1016/j.jcis.2017.03.006.

Kumar, K. et al. (2017) 'Food waste: a potential bioresource for extraction of nutraceuticals and bioactive compounds', Bioresources and Bioprocessing. Springer Berlin Heidelberg, 4(1). doi: 10.1186/s40643-017-0148-6.

Kushairi, A. et al. (2019) 'Oil palm economic performance in Malaysia and r\&d progress', Journal of Oil Palm Research. Lembaga Minyak Sawit Malaysia, pp. 165-194. doi: 10.21894/jopr.2019.0026.

Kusumayanti, H., Handayani, N. A. and Santosa, H. (2015) 'Swelling Power and Water Solubility of Cassava and Sweet Potatoes Flour', Procedia Environmental Sciences. Elsevier B.V., 23(Ictcred 2014), pp. 164-167. doi: 10.1016/j.proenv.2015.01.025.

Lai, Y. C. et al. (2016) 'Physicochemical properties of starches and expression and activity of starch biosynthesis-related genes in sweet potatoes', Food Chemistry. Elsevier Ltd, 199, pp. 556-564. doi: 10.1016/j.foodchem.2015.12.053.

Lattanzio, V., Cardinali, A. and Linsalata, V. (2012) Plant Phenolics: A Biochemical and Physiological Perspective, Wiley Online Library. Available at: https://onlinelibrary.wiley.com/doi/pdf/10.1002/9781118299753\#page=28 (Accessed: 28 May 2020).

Madruga, M. S. et al. (2014) 'Chemical, morphological and functional properties of Brazilian jackfruit (Artocarpus heterophyllus L.) seeds starch', Food Chemistry. Elsevier Ltd, 143, pp. 440-445. doi: 10.1016/j.foodchem.2013.08.003.

Maniglia, B. C. and Tapia-Blácido, D. R. (2016) 'Isolation and characterization of starch from babassu mesocarp', Food Hydrocolloids. Elsevier, 55, pp. 47-55. doi: 10.1016/j.foodhyd.2015.11.001.

Moharrami, P. and Motamedi, E. (2020) 'Application of cellulose nanocrystals prepared from agricultural wastes for synthesis of starch-based hydrogel nanocomposites: Efficient and selective nanoadsorbent for removal of cationic dyes from water', Bioresource Technology. Elsevier, 313(June), p. 123661. doi: 10.1016/j.biortech.2020.123661.

Mohd. Noor, M. A. et al. (1999) 'Physico-chemical Properties of Oil Palm Trunk Starch', Willey Online Library, 51(8-9), pp. 293-301. doi: 10.1002/(sici)1521-379.

Murai, K. and Kondo, R. (2010) 'Extractable sugar contents of trunks from fruiting and nonfruiting oil palms of different ages', Springer, 57(2), pp. 140-148. doi: 10.1007/s10086-010-1144-z.

Myers H Raymond, M. C. and Cook, A. (2016) Response Surface Methodology: Process and Product 
Optimization Using Designed Experiments.

Nadhari, W. N. A. W. et al. (2013) 'Utilization of oil palm trunk waste for manufacturing of binderless particleboard: Optimization study’, BioResources, 8(2), pp. 1675-1696. doi: 10.15376/biores.8.2.16751696.

Qin, Y. et al. (2016) 'Characterization of starch nanoparticles prepared by nanoprecipitation: Influence of amylose content and starch type', Industrial Crops and Products. Elsevier B.V., 87, pp. 182-190. doi: 10.1016/j.indcrop.2016.04.038.

Rodić, L. and Wilson, D. (2017) 'Resolving Governance Issues to Achieve Priority Sustainable Development Goals Related to Solid Waste Management in Developing Countries', Sustainability. MDPI AG, 9(3), p. 404. doi: 10.3390/su9030404.

Sabour, M. R. and Amiri, A. (2017) 'Comparative study of ANN and RSM for simultaneous optimization of multiple targets in Fenton treatment of landfill leachate', Waste Management, 65, pp. 54-62. doi: 10.1016/j.wasman.2017.03.048.

Sharifi, H., Zabihzadeh, M. and Ghorbani, M. (2018) 'The application of response surface methodology on the synthesis of conductive polyaniline/cellulosic fiber nanocomposites', Carbohydrate Polymers, 194(February), pp. 384-394. doi: 10.1016/j.carbpol.2018.04.083.

Sulaiman, N. S. et al. (2013) 'Evaluation of the properties of particleboard made using oil palm starch modified with epichlorohydrin', BioResources, 8(1), pp. 283-301. doi: 10.15376/biores.8.1.283-301.

Syamsul Bahri, D. (2016) 'Oil Palm by Product: How to Compute Its Cost of Production', IOSR Journal of Business and Management, 18(10), pp. 6-09. doi: 10.9790/487X-1810010609.

Tan, X. Y. and Ho, S. (2019) Oil palm planted areas to be capped at 6.5 million hectares|The Edge Markets, The Edge Market. Available at: https://www.theedgemarkets.com/article/oil-palm-plantedareas-be-capped-65-million-hectares.

Waterschoot, J. et al. (2015) 'Production, structure, physicochemical and functional properties of maize, cassava, wheat, potato and rice starches', Starch/Staerke, 67(1-2), pp. 14-29. doi: $10.1002 /$ star.201300238.

Wei, C. et al. (2019) 'Adsorption thermodynamic characteristics of Chlorella vulgaris with organic polymer adsorbent cationic starch: Effect of temperature on adsorption capacity and rate', Bioresource Technology. Elsevier, 293(July), pp. 1-8. doi: 10.1016/j.biortech.2019.122056.

$\mathrm{Wu}$, J. et al. (2020) 'Pre-acidification greatly improved granules physicochemical properties and operational stability of Upflow anaerobic sludge Blanket (UASB) reactor treating low-strength starch wastewater', Bioresource Technology, 302(June 2019), pp. 1-10. doi: 10.1016/j.biortech.2020.122810.

Yanita, M. and Qoirina, N. (2019) 'The impact of replanting oil palm plantations on the farming income of the Sungai Bahar community in Muaro Jambi Regency', Earth and Environmental Science, 012003(336), pp. 1-8. doi: 10.1088/1755-1315/336/1/012003.

Yusoff, M. S. et al. (2019) 'Potential use of oil palm trunk starch as coagulant and coagulant aid in semiaerobic landfill leachate treatment', Water Quality Research Journal, 54(3), pp. 203-219. doi: 10.2166/wqrj.2019.041.

Zamri, F. M. A., Mohd Akhiar, A. and Halim Shamsuddin, A. (2019) 'Talking Points of Green and Sustainable Palm Oil Mill System in Malaysia The effectiveness of oil palm trunk waste derived coagulant for landfill leachate treatment View project', International Journal of Recent Technology and Engineering, 8(4), pp. 6474-6479. doi: 10.35940/ijrte.D5160.118419.

Zhu, F. (2019) 'Recent advances in modifications and applications of sago starch', Food Hydrocolloids, 96, pp. 412-423. doi: 10.1016/j.foodhyd.2019.05.035. 
Zhu, Z. and Guo, W. (2017) 'Frequency, moisture content, and temperature dependent dielectric properties of potato starch related to drying with radio-frequency/microwave energy', Scientific Reports. Nature Publishing Group, 7(1), pp. 1-11. doi: 10.1038/s41598-017-09197-y. 
Figures
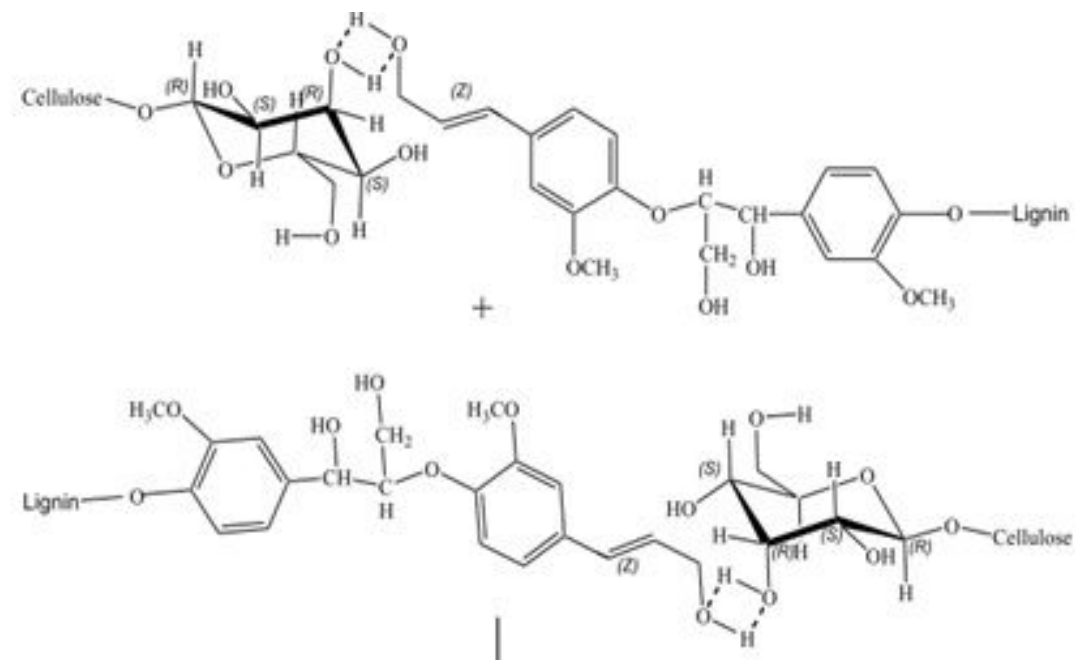

\section{Figure 1}

Bonding arrangement of oil palm trunk (Nadhari et al., 2013)
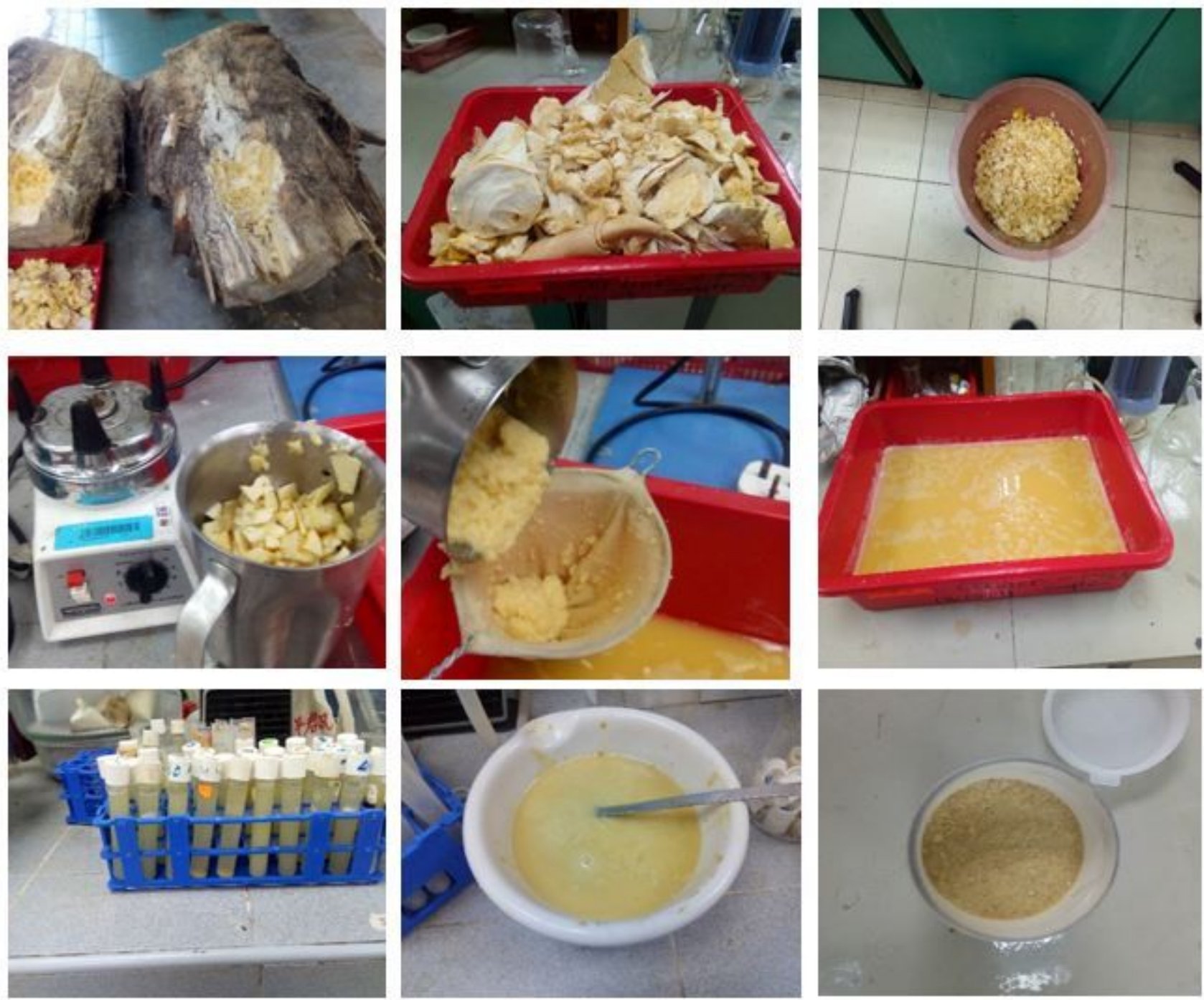
Figure 2

Extraction of starch from oil palm trunk
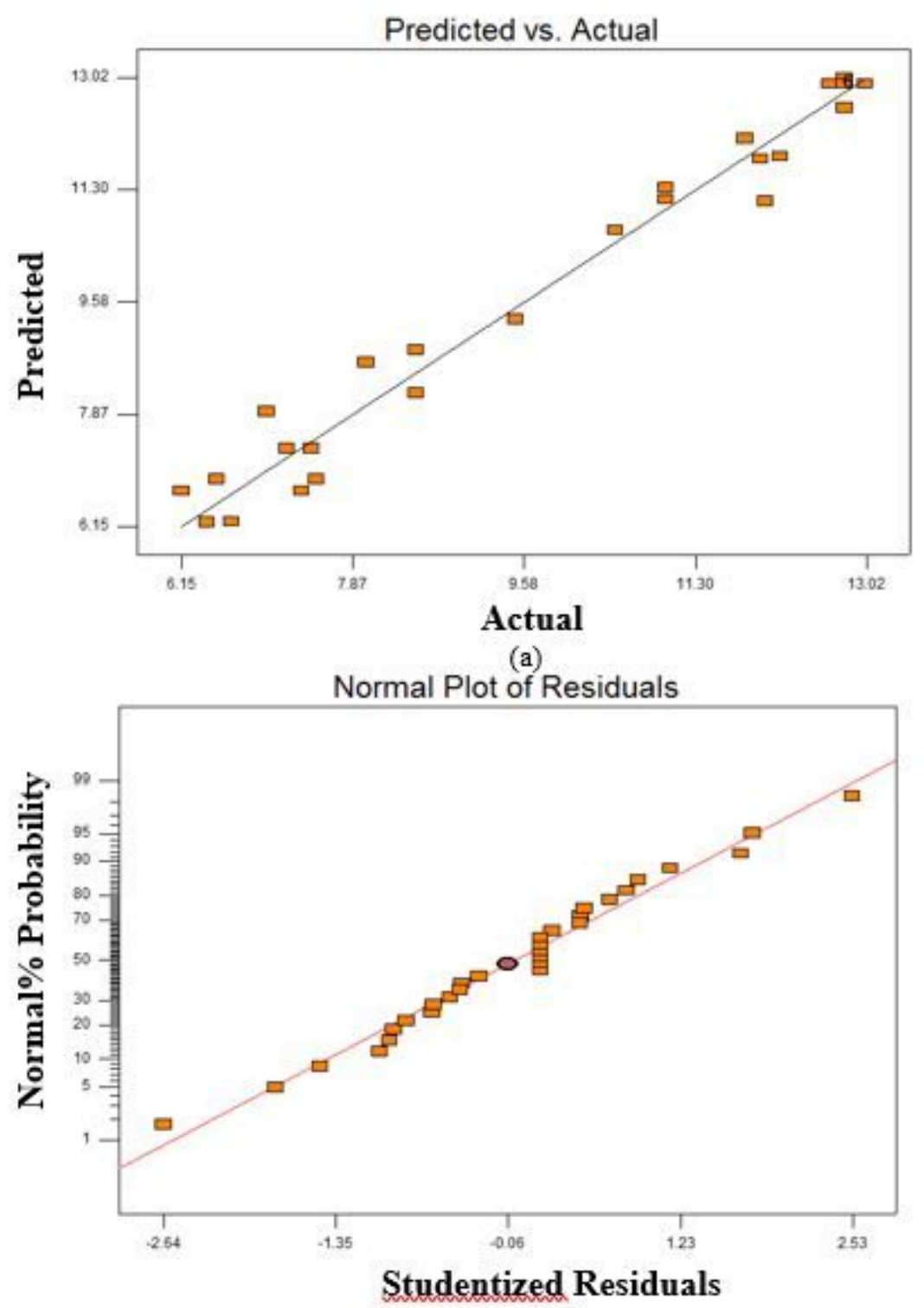

(b)

Figure 3

Design Expert originated plot (a) actual vs predicted; (b) Normal probability plot of the residuals 
†

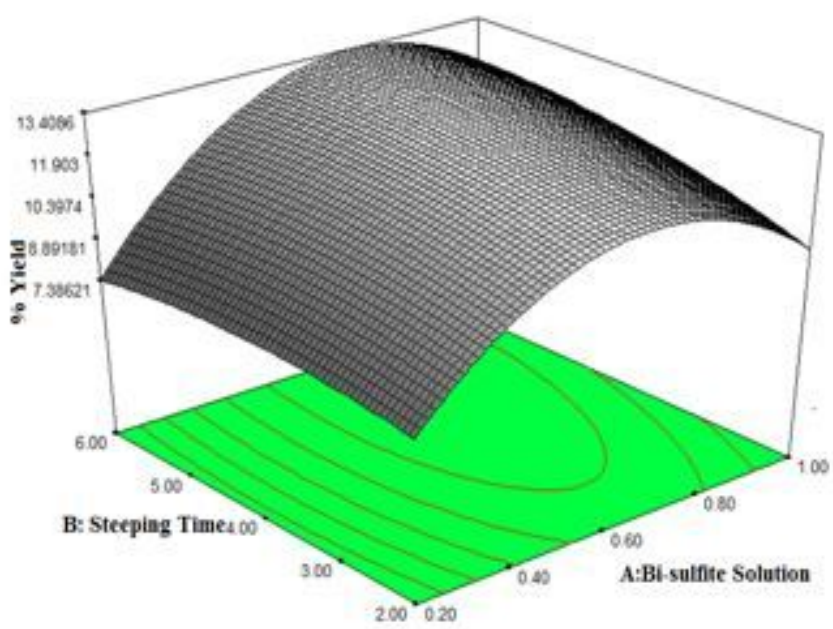

(a)

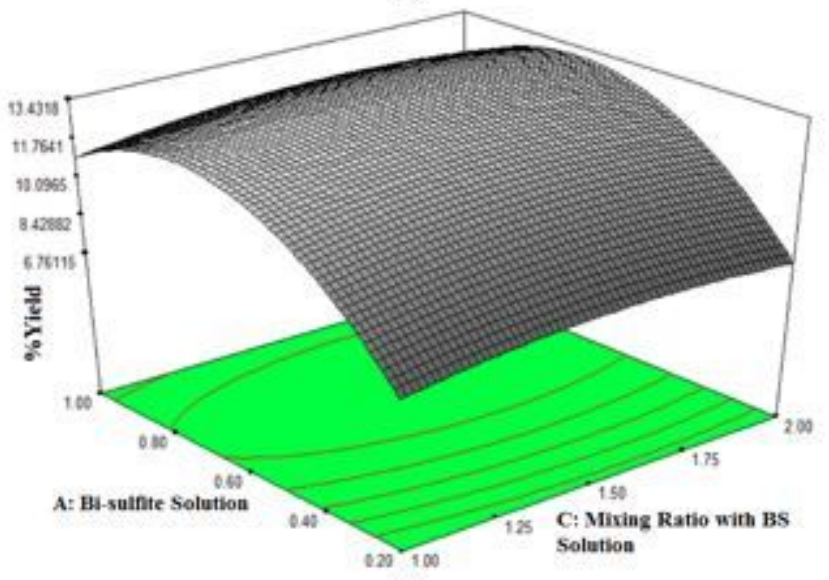

(c)

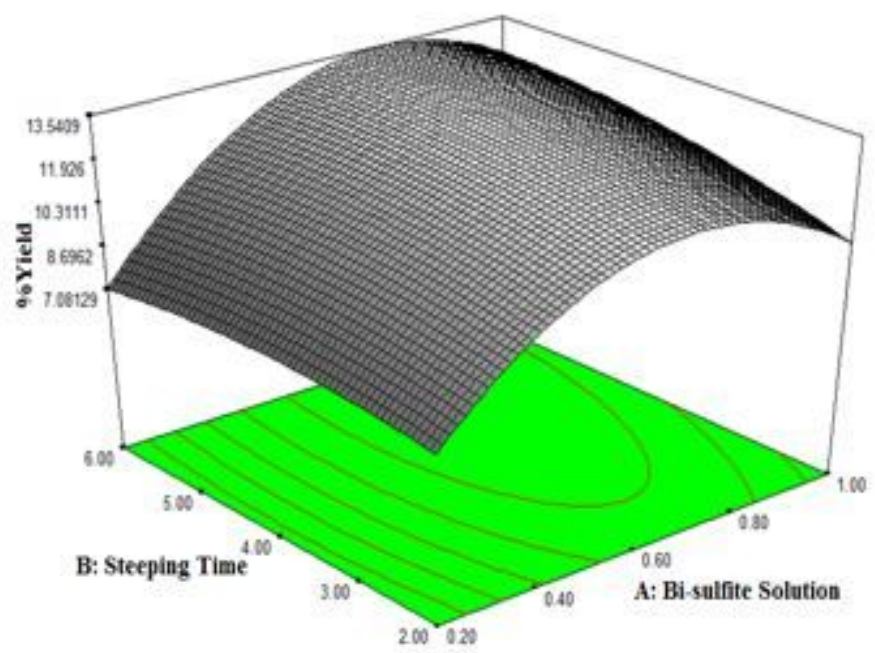

(b)

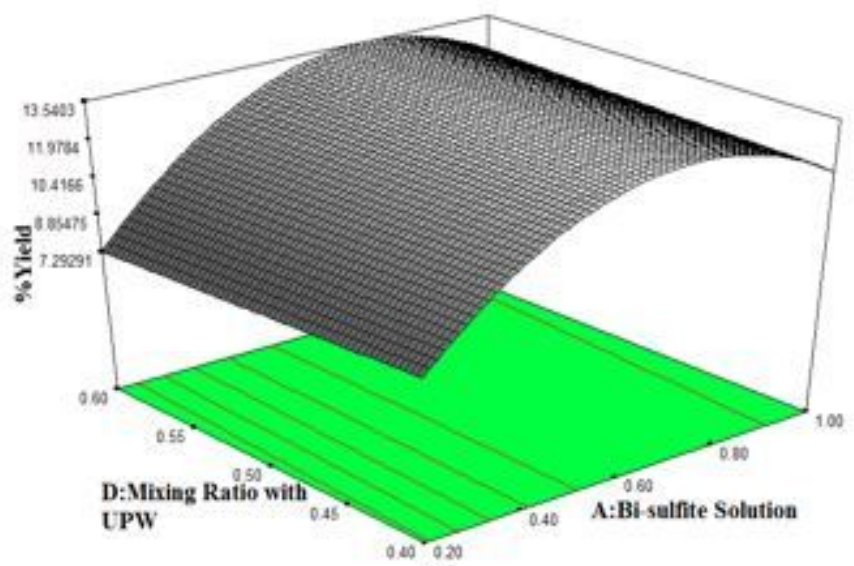

(d)

\section{Figure 4}

3D Response Surface Plot, (a) model graph from ANOVA; (b), (c), (d) numerical Optimization based on interrelation of parameters

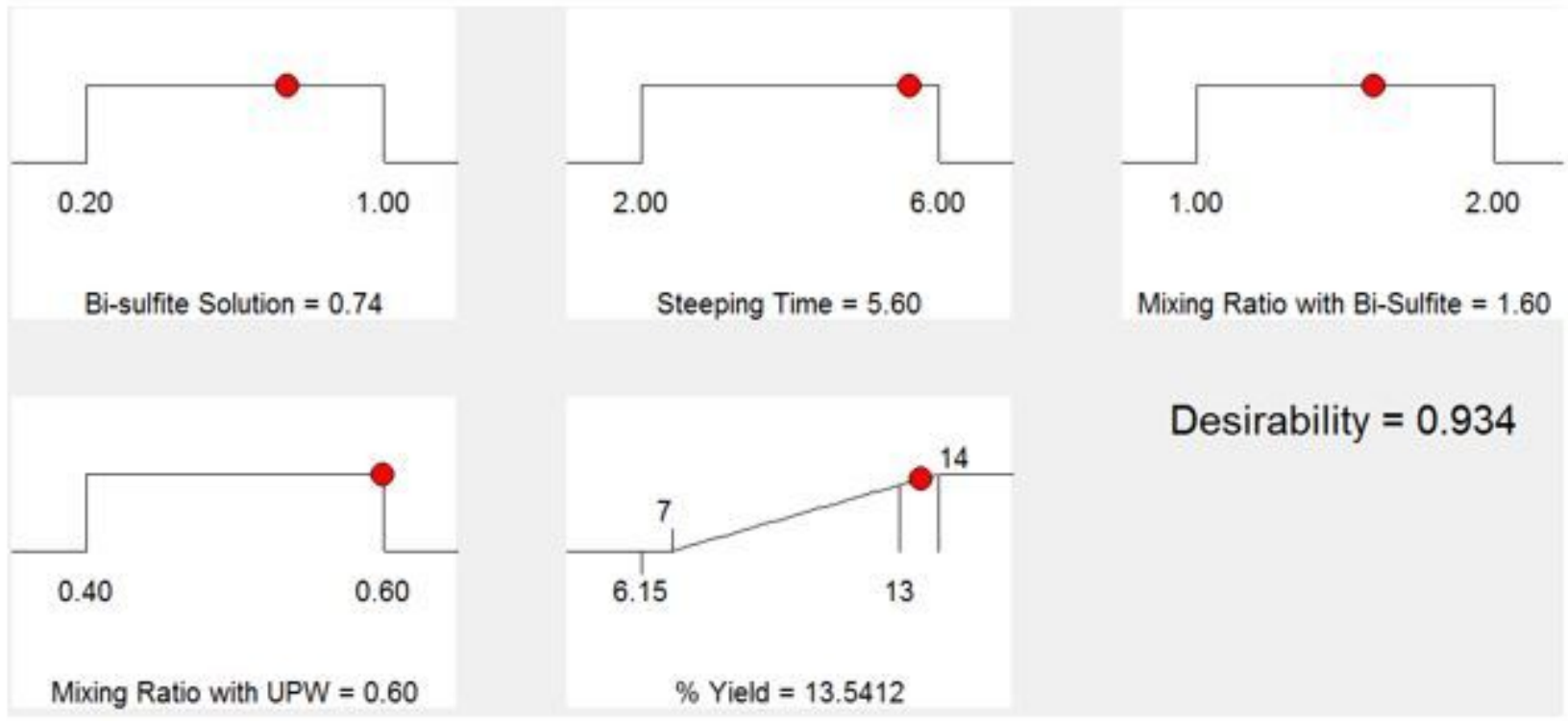


Figure 5

Desirability ramp for numerical optimization for four parameters and one response

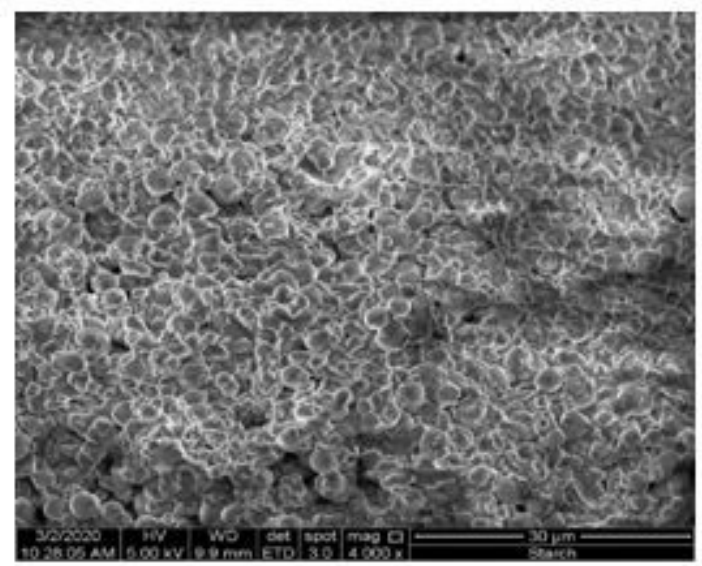

(a)

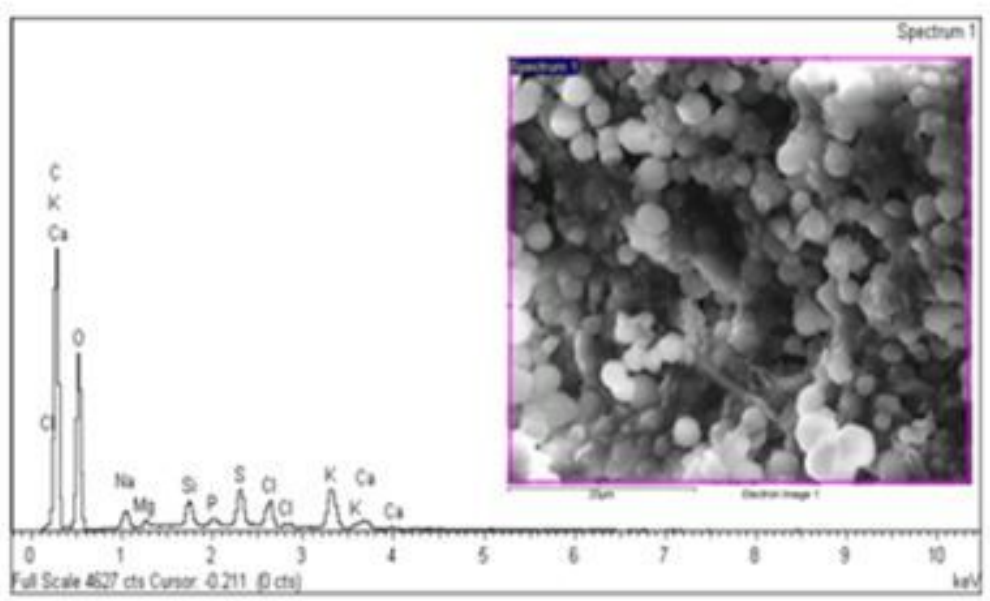

(c)

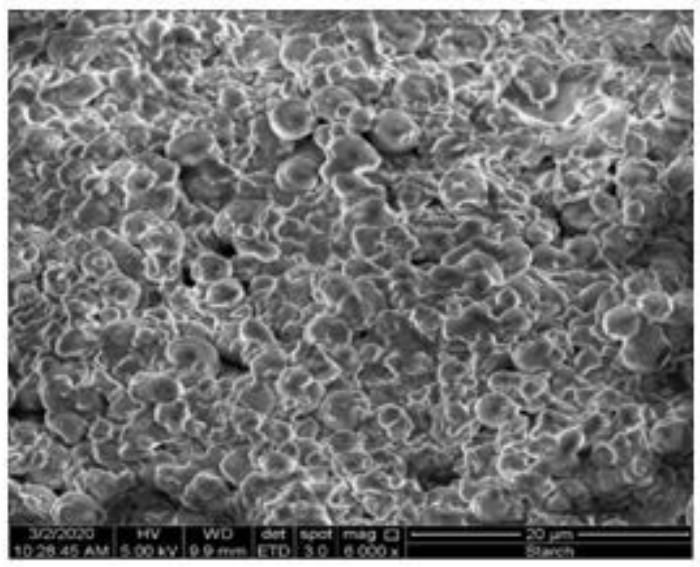

(b)

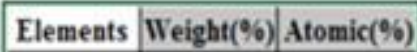

\begin{tabular}{|c|c|c|}
\hline $\mathrm{C} \mathrm{K}$ & 55.83 & 64.62 \\
\hline $\mathrm{OK}$ & 37.3 & 32.42 \\
\hline $\mathrm{NaK}$ & 0.8 & 0.48 \\
\hline $\mathrm{MgK}$ & 0.21 & 0.12 \\
\hline $\mathrm{SiK}$ & 0.77 & 0.38 \\
\hline $\mathrm{PK}$ & 0.28 & 0.13 \\
\hline $\mathrm{SK}$ & 1.38 & 0.6 \\
\hline $\mathrm{ClK}$ & 1.13 & 0.44 \\
\hline $\mathrm{K} \mathrm{K}$ & 1.89 & 0.67 \\
\hline $\mathrm{CaK}$ & 0.42 & 0.15 \\
\hline Totals & 100 & \\
\hline
\end{tabular}

\section{Figure 6}

(a) SEM micrograph of native starch at 4000 magnification; 7(b) SEM micrograph of native starch at 6000 magnification; 7(c) EDX analysis report for OPTS 


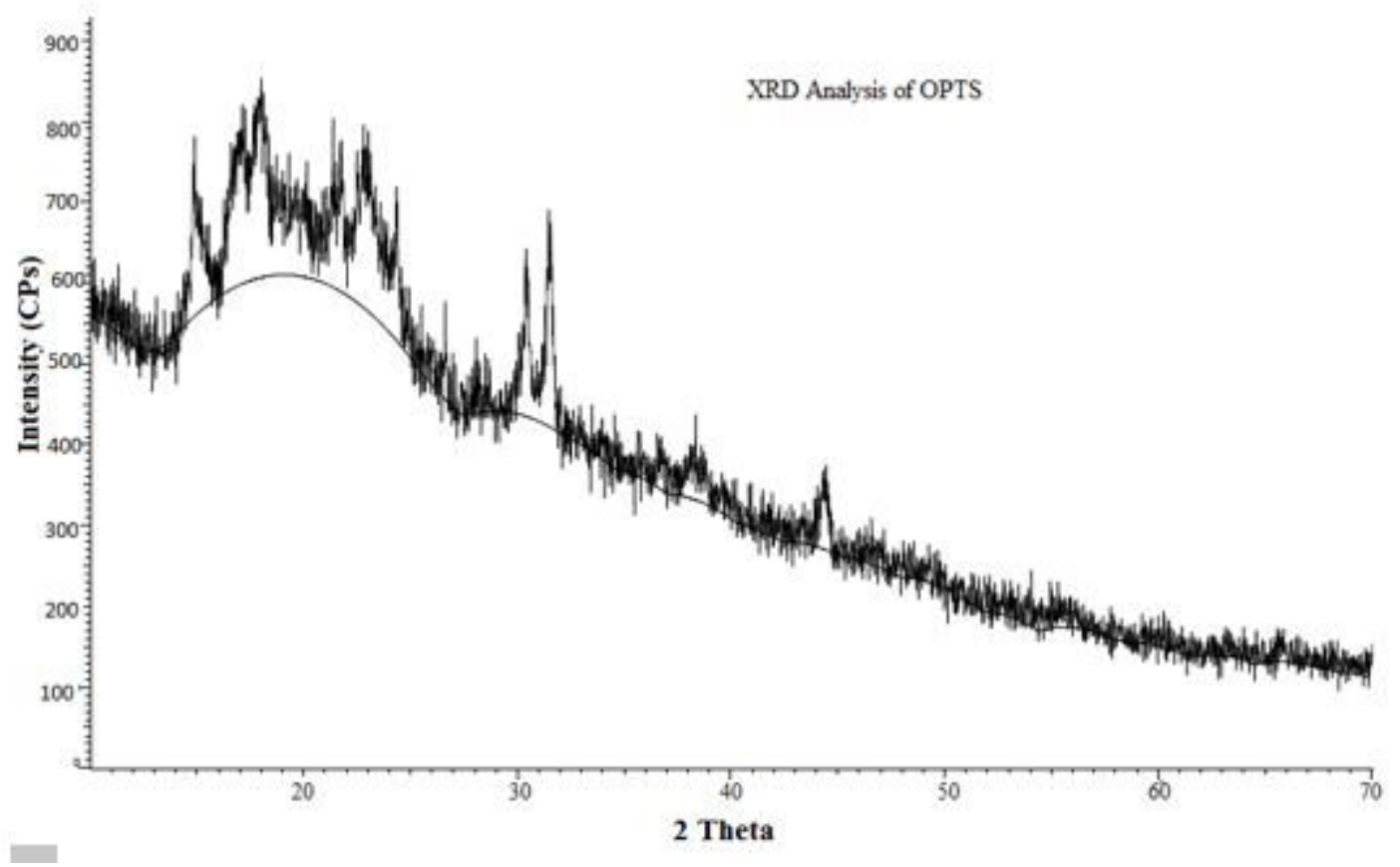

Figure 7

XRD analytical shape of OPTS

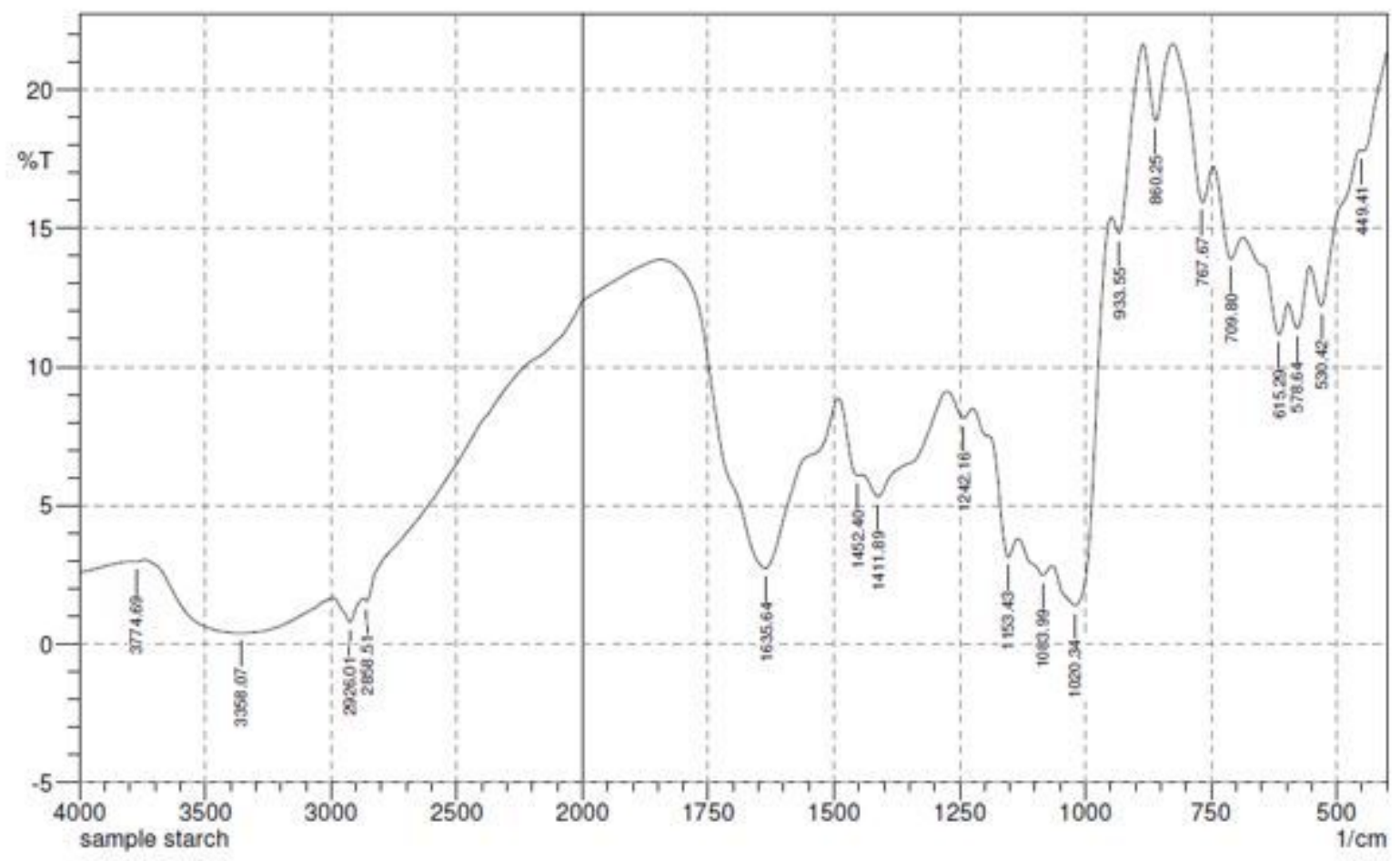

Figure 8

FTIR spectrum for extracted starch (OPTS)

\section{Supplementary Files}


This is a list of supplementary files associated with this preprint. Click to download.

- GraphAbsBRBPZA.png 